GABRIEL PEREIRA DAS NEVES

Modeling, construction and control of a self-balancing unicycle 
GABRIEL PEREIRA DAS NEVES

\section{Modeling, construction and control of a self-balancing unicycle}

Dissertation submitted to Escola Politécnica of the Universidade de São Paulo for degree of Master of Science. 


\section{GABRIEL PEREIRA DAS NEVES}

\section{Modeling, construction and control of a self-balancing unicycle}

Dissertation submitted to Escola Politécnica of the Universidade de São Paulo for degree of Master of Science.

Concentration area:

3139 - System engineering

Advisor:

Prof. Dr. Bruno Augusto Angélico 
Este exemplar foi revisado e corrigido em relação à versão original, sob responsabilidade única do autor e com a anuência de seu orientador.

São Paulo, de de

Assinatura do autor:

Assinatura do orientador:

Catalogação-na-publicação

Pereira das Neves, Gabriel

Modeling, construction and control of a self-balancing unicycle / G.

Pereira das Neves -- versão corr. -- São Paulo, 2017.

$74 \mathrm{p}$.

Dissertação (Mestrado) - Escola Politécnica da Universidade de São Paulo. Departamento de Engenharia de Telecomunicações e Controle.

1.CONTROLE LINEAR 2.ROBÓTICA 3.CONTROLE ÓTIMO I.Universidade de São Paulo. Escola Politécnica. Departamento de Engenharia de Telecomunicações e Controle II.t. 


\section{ACKNOWLEDGMENTS}

To Prof. Dr. Bruno Augusto Angélico, for his guidance, friendship, trust and all the help during the whole work.

To my mother Cassia Maria Pereira, my sisters Fernanda Pereira das Neves, Marina Pereira das Neves and Bianca Pereira das Neves and my girlfriend Rayra Destro, for supporting my decisions and helping me walk this path.

To Arthur Castello Branco de Oliveira, Fabio Yukio Toriumi, Fernando dos Santos Barbosa, Giovanni Gallon Neto, Mateus Mussi Brugnolli, all the other members of the Laboratório de Controle Aplicado (LCA) and André Marcorin de Oliveira for the help and discussions in the LCA and the friendship that we formed.

To Prof. Dr. José Jaime da Cruz and Paulo Sérgio Pereira da Silva, for participating on the qualification, comments and suggestions.

To professors Dr. Cristiano Marcos Agulhari and Flavius Portella Ribas Martins for helping with problema faced during the project.

To Prof. Dr. Fuad Kassab Junior for helping with the project.

To laboratory technician Kennedy Xisto Barros Peixoto whose help became indispensable in the construction of the unicycle.

To all who helped, directly or indirectly, throughout the project.

To the Laboratório de Automação e Controle (LAC) of the Escola Politécnica of USP for the availability of physical resources.

To Fundação de Amparo à Pesquisa do Estado de São Paulo (FAPESP) for the finance of the project, process 2016/00729-9. 
"Knowing your own ignorance is the first step to enlightenment"

-Patrick Rothfuss 


\section{RESUMO}

Neste trabalho, é apresentado um sistema de um monociclo com roda de reação, mostrando desde a construção, passando pela modelagem até o projeto e teste dos controladores.

Primeiramente, é feito o projeto mecânico por meio de um desenho assistido por computador tridimensional (3D CAD), para auxiliar a construção e, em seguida, a modelagem por meio do método de Lagrange. Naturalmente, o sistema é não linear e os ângulos de arfagem e rolamento são acoplados. Neste trabalho, controladores lineares são projetados e, portanto, a linearização do sistema é feita pelo Jacobiano, ou seja, assumindo pequenas variações em torno do ponto de equilíbrio. Nesta situação, o modelo desacopla os ângulos de arfagem e rolamento.

O protótipo é construído fixando os componentes eletrônicos, a bateria, as rodas e os motores a um corpo, de forma a ser totalmente autônomo. O posicionamento das peças precisa ser equilibrado, de forma a manter a posição do centro de massa ao longo dos eixos de simetria vertical e horizontal.

Em seguida, é feito um projeto de controle linear para estabilização da planta usando duas técnicas que são validadas via simulações do sistema não linear acoplado. Depois, as técnicas são testadas no protótipo construído.

A primeira consiste do controle ótimo LQR que, apesar de ter funcionado, apresentou alguns problemas devidos a incertezas paramétricas.

Logo, é usado o controle $\mathcal{H}_{2}$ via LMI, de tal forma que o projeto equivalha ao LQR, mas desta forma é possível inserir incertezas paramétricas e achar um controlador com algum grau de robustez a elas.

Palavras-Chave - Monociclo, Roda de reação, Controle LQR, Controle $\mathcal{H}_{2}$, LMI. 


\section{ABSTRACT}

In this work, a unicycle system with reaction wheel is presented, considering the construction, the modeling, the design and test of the controllers.

Firstly, a mechanical model considering a tridimensional computer aided design (3D CAD) is built in order to assist the construction and, after that, the modeling using the Lagrange method. In this work, linear controllers are designed and, therefore, the linearization of the system is done by the Jacobian, that is, assuming small variations around the equilibrium point. In this situation, there is no coupling between the pitch and the roll angles, thus resembling two inverted pendulums.

The prototype is constructed by attaching the electronic components, the battery, the wheels and the motors to a body, to make it fully autonomous. The positioning of the parts has to balanced in order to maintain the position of the center of mass along the vertical and horizontal axis of symmetry.

Then, a linear control project is done to stabilize the plant using two techniques that are validated considering simulations of the nonlinear coupled system. Then, the techniques were tested in the built prototype.

The first one consists of the optimal LQR control that, although it worked, presented some problems due to parametric uncertainties.

Therefore, the $\mathcal{H}_{2}$ control is used via LMI in such a way that the project becomes similar to the LQR, but in this way it is possible to insert parametric uncertainties and find a controller with some degree of robustness to them.

Keywords - Unicycle, Reaction wheel, LQR control, $\mathcal{H}_{2}$ control, LMI. 


\section{LIST OF FIGURES}

Figure 1 Example of a unicycle. . . . . . . . . . . . . . . . . . . . 19

Figure 2 Another example of a unicycle . . . . . . . . . . . . . . . . 19

Figure 3 Example of a unicycle with a bar. . . . . . . . . . . . . . . . 20

Figure 4 Example of a unicycle with a gyroscopic system. . . . . . . . . . . 20

Figure 5 Schematic drawing. . . . . . . . . . . . . . . . . 21

Figure 6 Unicycle body . . . . . . . . . . . . . . . . . . . . 22

Figure $7 \quad$ Bearing and Axle. . . . . . . . . . . . . . . . . 23

Figure 8 Unicycle's wheel. . . . . . . . . . . . . . . . . . . . . 23

Figure 9 Schematic drawing. . . . . . . . . . . . . . . . . . . 24

Figure 10 Free body diagram. . . . . . . . . . . . . . . . . . 24

Figure 11 Unicycle's reaction wheel. . . . . . . . . . . . . . . . 25

Figure 12 Unicycle motors . . . . . . . . . . . . . . . . . . 26

Figure 13 Microcontroller. . . . . . . . . . . . . . . . . . . . 28

Figure 14 Schematic drawing of electronic components arrangement. . . . . . 29

Figure 15 Motor driver. . . . . . . . . . . . . . . . . . . . . . 29

Figure 16 IMU Sensor. . . . . . . . . . . . . . . . . . . . . 30

Figure 17 Schematic drawing ...................... 31

Figure 18 Practical unicycle . . . . . . . . . . . . . . . . . . 32

Figure 19 Positions of the bodies. . . . . . . . . . . . . . . . 34

Figure 20 Projection of $\overrightarrow{p_{1}}$ on the $y z$ plane. . . . . . . . . . . . . . 34

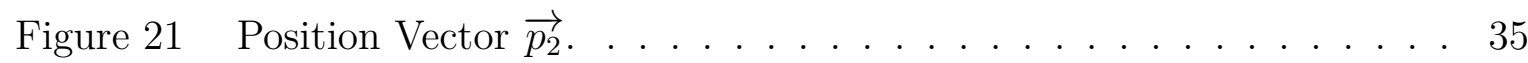

Figure 22 Projection of $\overrightarrow{p_{2}}$ on the $y z$ plane. . . . . . . . . . . . . 36

Figure 23 Position Vector $\overrightarrow{p_{3}} \ldots \ldots \ldots \ldots \ldots \ldots$ 
Figure 24 Simulation of the LQR controller. . . . . . . . . . . . . . . . . . 52

Figure 25 Control effort which LQR controller. . . . . . . . . . . . . . . . . 52

Figure 26 Simulation of the LQR considering noise and dead zone. . . . . . . 53

Figure 27 Control effort with LQR considering noise and dead zone. . . . . . . 54

Figure 28 Simulation of the $\mathcal{H}_{2}$ controller. . . . . . . . . . . . . . . . . 55

Figure 29 Control effort with $\mathcal{H}_{2}$ controller. . . . . . . . . . . . . . . . . . . 55

Figure 30 Simulation with $\mathcal{H}_{2}$ controller considering noise and dead zone. . . . 56

Figure 31 Control effort of the $\mathcal{H}_{2}$ considering noise and dead zone. . . . . . . 56

Figure 32 Practical stabilization test with LQR. . . . . . . . . . . . . 57

Figure 33 Practical roll angle disturbance test with LQR. . . . . . . . . . . 58

Figure 34 Practical pitch angle disturbance test with LQR. . . . . . . . . . . . 58

Figure 35 Practical pitch and roll angle disturbance test with LQR. . . . . . . 59

Figure 36 Practical stabilization test with $\mathcal{H}_{2}$ controller. . . . . . . . . . . 60

Figure 37 Practical roll angle disturbance test with $\mathcal{H}_{2}$ controller. . . . . . . . 60

Figure 38 Practical pitch angle disturbance test with $\mathcal{H}_{2}$ controller. . . . . . . 61

Figure 39 Practical pitch and roll angle disturbance test with $\mathcal{H}_{2}$ controller. . 61

Figure 40 Position of the center of mass . . . . . . . . . . . . . . 63

Figure 41 Principal Diagram. . . . . . . . . . . . . . . . . . 70

Figure 42 Block 1. . . . . . . . . . . . . . . . . . 71

Figure 43 Block 2. . . . . . . . . . . . . . . . . . 71

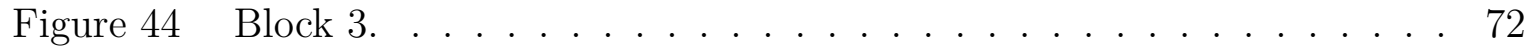




\section{LIST OF TABLES}

Table 1 Physical Parameters . . . . . . . . . . . . . . 27

Table 2 Drive operation . . . . . . . . . . . . . . 30 


\section{LIST OF ABBREVIATIONS}

$3 \mathrm{D}$

CAD

CARE

$\mathrm{CM}$

FAPESP

IMU

LAC

LCA

LMI

LQR

PWM

rpm

USP

Tridimensional

Computer-aided design

Continuous algebraic Riccati equation

Center of mass

Fundação de Amparo à Pesquisa do Estado de São Paulo

Inertial measurement unit

Laboratório de Automação e Controle

Laboratório de Controle Aplicado

Linear matrix inequality

Linear quadratic regulator

Pulse width modulation

Rotation per minutes

Universidade de São Paulo 


\section{LIST OF SYMBOLS}

\begin{tabular}{|c|c|}
\hline$M_{r}$ & Mass of reaction wheel $[K g]$ \\
\hline$J_{r}$ & Reaction wheel moment of inertia $\left[\mathrm{Kgm}^{2}\right]$ \\
\hline$d_{r}$ & Distance of reaction wheel $[m]$ \\
\hline$M_{b} r$ & Mass of the body and travel wheel $[K g]$ \\
\hline$J_{b} r$ & Moment of inertia of body and wheel $\left[\mathrm{Kgm}^{2}\right]$ \\
\hline$d_{b}$ & Distance of the body $[m]$ \\
\hline$\varphi$ & Roll angle $[\mathrm{rad}]$ \\
\hline$\theta_{r}$ & Reaction wheel angle $[\mathrm{rad}]$ \\
\hline$R_{1}$ & Internal radius of reaction wheel $[\mathrm{m}]$ \\
\hline$R_{2}$ & Internal radius of reaction wheel $[\mathrm{m}]$ \\
\hline$\tau_{\text {dynamic }}$ & Dynamic torque $[\mathrm{Nm}]$ \\
\hline$\omega$ & Angular velociy $[\mathrm{rad} / \mathrm{s}]$ \\
\hline$\Delta t$ & Time variation $[s]$ \\
\hline$J$ & Moment of inertia $\left[\mathrm{Kgm}^{2}\right]$ \\
\hline$\tau_{t}$ & Time constant of the filter $[1 / s]$ \\
\hline$R_{r}$ & Reaction wheel radius $[m]$ \\
\hline$R_{w}$ & Wheel radius $[m]$ \\
\hline$L$ & Distance of the center of mass $(\mathrm{CM})$ of the body $[\mathrm{m}]$ \\
\hline$d$ & Distance between the $\mathrm{CM}$ of the body and reaction wheel $[\mathrm{m}]$ \\
\hline$M_{r}$ & Reaction wheel mass $[K g]$ \\
\hline$M_{b}$ & Body mass $[K g]$ \\
\hline$M_{w}$ & Wheel mass $[K g]$ \\
\hline$g$ & Acceleration of gravity $\left[\mathrm{m} / \mathrm{s}^{2}\right]$ \\
\hline$J_{w}$ & Wheel moment of inertia $\left[\mathrm{Kgm}^{2}\right]$ \\
\hline$J_{b r}$ & Moment of inertia of the body plus reaction wheel $\left[\mathrm{Kgm}^{2}\right]$ \\
\hline$J_{b w}$ & Moment of inertia of the body plus wheel $\left[\mathrm{Kgm}^{2}\right]$ \\
\hline
\end{tabular}




\begin{tabular}{|c|c|}
\hline$n_{r}$ & Reduction of the reaction wheel motor \\
\hline$K_{t r}$ & Torque constant of the reaction wheel motor $[\mathrm{Nm} / \mathrm{A}]$ \\
\hline$K_{e r}$ & Electrical constant of the reaction wheel motor $\left[\mathrm{Vs}^{2} / \mathrm{rad}\right]$ \\
\hline$R_{e r}$ & Electrical resistance of the reaction wheel motor $[\Omega]$ \\
\hline$n_{w}$ & Reduction of the wheel motor \\
\hline$K_{t w}$ & Torque constant of the wheel motor $[N m / A]$ \\
\hline$K_{e w}$ & Electrical constant of the reaction wheel motor $\left[\mathrm{Vs}^{2} / \mathrm{rad}\right]$ \\
\hline$R_{e w}$ & Electrical resistance of the wheel motor $[\Omega]$ \\
\hline$B_{v w}$ & Travel wheel viscous friction $\left[N s^{2} / \mathrm{rad}\right]$ \\
\hline$B_{v r}$ & Reaction wheel viscous friction $\left[N s^{2} / \mathrm{rad}\right]$ \\
\hline$I N A$ & Rotation direction controller \\
\hline$I N B$ & Rotation direction controller \\
\hline$V_{\text {out }}$ & Output voltage of the drive $[V]$ \\
\hline$V_{\text {in }}$ & Input voltage of the drive $[V]$ \\
\hline$\psi$ & Pitch angle $[\mathrm{rad}]$ \\
\hline$\varphi_{\text {gyro }}$ & Gyroscope measurement \\
\hline$\varphi_{\text {bias }}$ & Bias \\
\hline$K_{k}$ & Kalman gain \\
\hline$P_{k}$ & Estimation error covariance \\
\hline$\vec{x}$ & $\mathrm{x}$ axis \\
\hline$\vec{y}$ & y axis \\
\hline$\vec{z}$ & $\mathrm{z}$ axis \\
\hline$a_{x}$ & Acceleration in direction $\vec{x}$ \\
\hline$a_{y}$ & Acceleration in direction $\vec{y}$ \\
\hline$a_{z}$ & Acceleration in direction $\vec{z}$ \\
\hline $\overrightarrow{p_{1}}$ & Position of wheel center of mass \\
\hline $\overrightarrow{p_{2}}$ & Position of body center of mass \\
\hline $\overrightarrow{p_{3}}$ & Position of reaction wheel center of mass \\
\hline$\theta_{w}$ & Wheel angle $[\mathrm{rad}]$ \\
\hline
\end{tabular}


$\overrightarrow{p_{L}}$

$\overrightarrow{p_{d}}$

M

$\vec{v}$

$\overrightarrow{v_{1}}$

$\overrightarrow{v_{2}}$

$\overrightarrow{v_{3}}$

$E_{T}$

$E_{R}$

U

$g$

$L$

$q$

$\tau$

$\tau_{r}$

$\tau_{w}$

$P W M_{r}$

$P W M_{r}$

$n_{r}$

$n_{w}$

$M(q), V(q, \dot{q}), G(q)$

$x$

$A, B, C$

$\lambda$

$\mathfrak{C}$

$Q, R$

P
Vector with origin in the wheel center of mass and the extremity in the body center of mass

Vector with origin in the body center of mass and the extremity in the reaction wheel center of mass

Mass of the object $[K g]$

Velocity vector of the center of mass $[\mathrm{m} / \mathrm{s}]$

Velocity of wheel center of mass $[\mathrm{m} / \mathrm{s}]$

Velocity of body center of mass $[\mathrm{m} / \mathrm{s}]$

Velocity of reaction wheel center of mass $[\mathrm{m} / \mathrm{s}]$

Translational kinetic energy

Rotational kinetic energy

Potential energy

Acceleration of gravity $\left[\mathrm{m} / \mathrm{s}^{2}\right]$

Lagrangian

Variable of the degree of freedom

External torque $[\mathrm{Nm}]$

Torque of the motor connect to the reaction wheel $[\mathrm{Nm}]$

Torque of the motor connect to the travel wheel $[\mathrm{Nm}]$

PWM signal of the reaction wheel motor [\%]

PWM signal of the travel wheel motor [\%]

Motor reduction of the reaction wheel

Motor reduction of the travel wheel

Matrices of the non-linear model

State vector

Matrices of the linear model

Eigenvalues

Controllability matrix

Matrices of LQR project

Solution of the Riccati equation and the symmetric matrix of Lyapunov 


$\begin{array}{ll}K_{L Q R} & \text { Feedback state designed by LQR } \\ V(x) & \text { Lyapunov function } \\ w & \text { Exogenous input } \\ B_{w} & \text { Matrix related to exogenous input } \\ z & \text { Controlled output for } \mathcal{H}_{2} \text { control } \\ C_{z}, D_{z} & \text { Matrices of the } z \\ W_{c} & \text { Controllability grammar } \\ A_{c l}, C_{c l} & \text { Closed loop matrices } \\ v, \mathcal{Q}, \mathcal{B}, \mathcal{X} & \text { Variables used in Finsler' Lemma } \\ \xi, H & \text { Controller design variables via LMI } \\ \alpha & \text { System index considering parametric errors } \\ \Xi & \text { Unit simplex } \\ K_{L M I} & \text { Feedback state designed by LMI } \\ T s & \text { Sample time }\end{array}$




\section{CONTENTS}

$\begin{array}{lll}1 & \text { Introduction } & 17\end{array}$

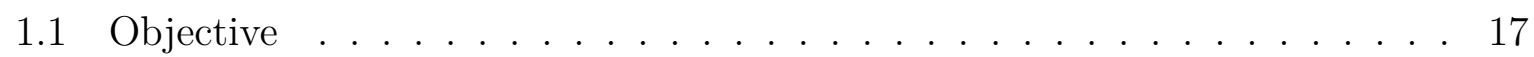

1.2 Justification . . . . . . . . . . . . . . . . . . . . . 18

1.3 Literature review . . . . . . . . . . . . . . . . . . . . . . . . 18

2 Construction $\quad 21$

2.1 Initial Concept . . . . . . . . . . . . . . . . . . 21

2.2 Body . . . . . . . . . . . . . . . . . . . . 22

2.3 Travel Wheel . . . . . . . . . . . . . . . . . . . . . . . . . 22

2.4 Reaction Wheel . . . . . . . . . . . . . . . . . . 22

2.5 DC Motors . . . . . . . . . . . . . . . . . . 26

2.6 Physical Parameters . . . . . . . . . . . . . . . . . . . . . 27

2.7 Electric Circuit . . . . . . . . . . . . . . . . . . . . . . . 28

2.7 .1 Motor Drive . . . . . . . . . . . . . . . . . . . . . . 28

2.7.2 Inertial Measurement Unit . . . . . . . . . . . . . . . . . 28

2.8 Unicycle built . . . . . . . . . . . . . . . . . . . . . . . 31

3 System Modeling $\quad 33$

3.1 Non-Linear Model . . . . . . . . . . . . . . . . . . . . . . . 33

3.1.1 Position of the Unicycle . . . . . . . . . . . . . . . 33

3.1.2 Energy Calculation . . . . . . . . . . . . . . . 37

3.1 .3 Lagrange Equation . . . . . . . . . . . . . . . . . . . . 38

$3.2 \quad$ Linear Model . . . . . . . . . . . . . . . . . . . . . . . . . . . . . . . . 39

3.2 .1 Jacobian . . . . . . . . . . . . . . . . . . . 40 
3.3 Linear Model Analysis . . . . . . . . . . . . . . . . . . . . . . . . . . . . 42

3.3 .1 Stability . . . . . . . . . . . . . . . . . 42

4 Control Strategies $\quad 43$

4.1 Linear Quadratic Regulator . . . . . . . . . . . . . . . . . . . 43

4.1.1 Linear Quadratic Regulator . . . . . . . . . . . . . . . . . . 43

4.1 .2 Bryson's rule . . . . . . . . . . . . . . . . 43

4.1.3 Control of the simplified model . . . . . . . . . . . . . . . . . . . 44

4.2 Linear matrix inequality . . . . . . . . . . . . . . . . . . 45

$4.2 .1 \quad$ Norm $\mathcal{H}_{2} \quad \ldots \ldots \ldots \ldots \ldots$

4.2 .2 Parametric uncertainties . . . . . . . . . . . . . . 48

5 SIMULATION AND PRACTICAL RESULTS 51

5.1 Simulation of the LQR controller . . . . . . . . . . . . . . . . . 51

5.2 Simulation of the $\mathcal{H}_{2}$ controller . . . . . . . . . . . . . . . . 54

5.3 Practical results of the LQR . . . . . . . . . . . . . . . . 57

5.4 Practical results of the $\mathcal{H}_{2}$ controller . . . . . . . . . . . . . . . . . . . 59

6 Conclusions $\quad 63$

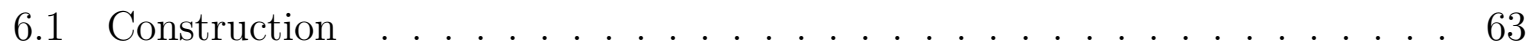

6.2 Controller .............................. 64

6.3 Future works . . . . . . . . . . . . . . . . . 65

$\begin{array}{ll}\text { References } & 66\end{array}$

$\begin{array}{ll}\text { Appendix A } & 68\end{array}$

$\begin{array}{lr}\text { Appendix B } & 70\end{array}$ 


\section{INTRODUCTION}

For robotic systems, the issue of balance is of fundamental importance. Several control studies approach this theme, and the most classic and didactic is the case of the inverted pendulum.

Many variations of the classical pendulum emerged over time, such as the Furuta pendulum (FURUTA; YAMAKITA; KOBAYASHI, 1991) and the pendulum with reaction wheel (JEPSEN et al., 2009), which uses the torque reaction applied to a wheel to stabilize it. This concept was expanded to the 3-D inverted pendulum, in the form of a cube, with reaction wheel (MUEHLEBACH; D'ANDREA, 2017).

The use of reaction wheel as actuator is widely used for space systems and satellites (CHOU et al., 2011), as well as in other control systems, such as the pendulums already mentioned, stabilization and assistance for motorcycle (TANOS; STEFFEN; MAVROS, 2014) and bipedal robot systems (BROWN; SCHMIEDELER, 2016).

Another widely used variation of the inverted pendulum is the is the segway (BIN; ZHEN; FENG, 2010), that is a locomotion system with two wheels, which is based on the inverted pendulum.

In this work there is a variation of an equilibrium system very similar to a segway but with only one wheel in contact with the ground, and using a reaction wheel to stabilize the roll angle.

\section{$1.1 \quad$ Objective}

The objective of the research is to construct a prototype of a unicycle with reaction wheel, to obtain a mathematical model and to test control techniques.

A simulator is developed to validate the control techniques that will be applied in the prototype. 
Finally, a document and all tools developed will be available for the institution to use in research and teaching applications.

\subsection{Justification}

The reaction wheel is widely used as actuator in different systems, making its application possibilities and study very meaningful.

In addition, the reaction wheel unicycle is a complex and recent control system. The unicycle construction is not broadly explored and, to the best of the authors knowledge, this is the first built in Latin America.

The project depends on several areas of engineering, because it contemplates the mechanical design and construction, mathematical modeling, design and simulation of the control and practical test, thus is a great system for learning a complete control project.

\subsection{Literature review}

There are some works in the literature regarding on this topic. A system similar to our work is a unicycle with a reaction wheel, in which the control of the pitch angle is made by the wheel in contact with the ground, the roll angle is controlled by the reaction of the torque applied to the reaction wheel. Figure 1 shows one of the prototypes built, in which were developed works applying sliding mode control, without considering parametric errors accurately, (HAN; LEE, 2015) and fuzzy control considering the decoupled system (LEE; HAN; LEE, 2013). It is worth mentioning that the wheel in contact with the ground has a flat pattern, which facilitates the roll stabilization.

The PID controller was applied to this system (ROSYIDI et al., 2016) in the prototype of Figure 2a, where the decoupled modeling was considered. Figure $2 \mathrm{~b}$ shows the prototype in which a LQR control was applied to the system to act on inclined planes, designed to operate with slopes of $\pm 11^{\circ}$.

Although unicycles with reaction wheel can be stabilized and, in some cases, considering also an velocity setpoint for both wheels, it is not easy to make them following a curve trajectory. For this, some works considered two reactions wheel, one for the roll angle and the other for the yaw angle control, as in (DAOXIONG; XIANG, 2013). This makes it possible for the unicycle to make curves (HWANG; KIM; LEE, 2010). 
Figure 1: Example of a unicycle.

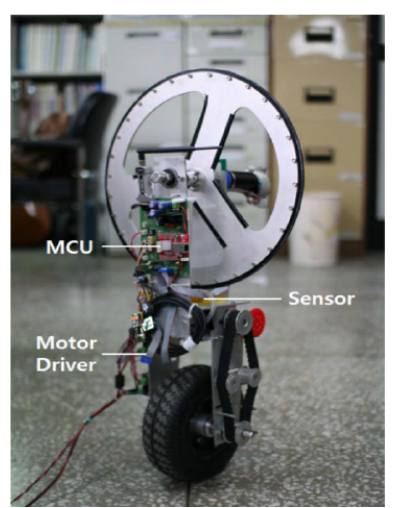

Source: (HAN; LEE, 2015) and (LEE; HAN; LEE, 2013).

Figure 2: Another example of a unicycle
(a) Exemple 2.
(b) Exemple 3.
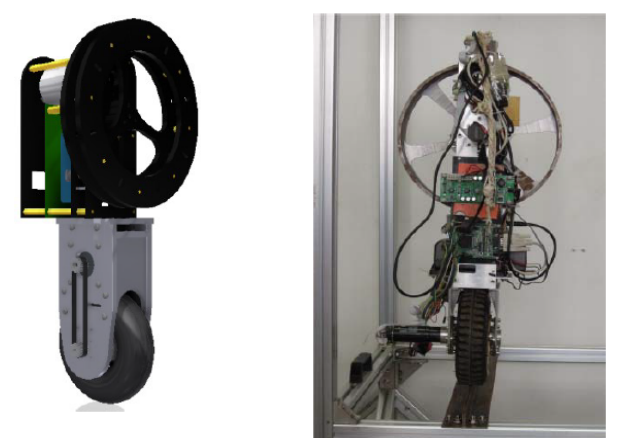

Source: (ROSYIDI et al., 2016) and (DAOXIONG GONG; QI, 2012)

Another type of unicycle was presented in (HU et al., 2014) in which the control of the roll angle is made by the displacement of a bar, and thus adjusting the position of the center of mass, and a motor with a reaction wheel for yaw angle control as shown in Figure 3. The LQR and PID controls were applied. In (GUO; HE; SONG, 2016), sliding mode control was applied to the same unicycle.

The most recent type of unicycle is proposed in (JIN et al., 2016), which controls the roll angle by means of the gyroscopic precession effect. Figure 4 shows the scheme of this system. 
Figure 3: Example of a unicycle with a bar.

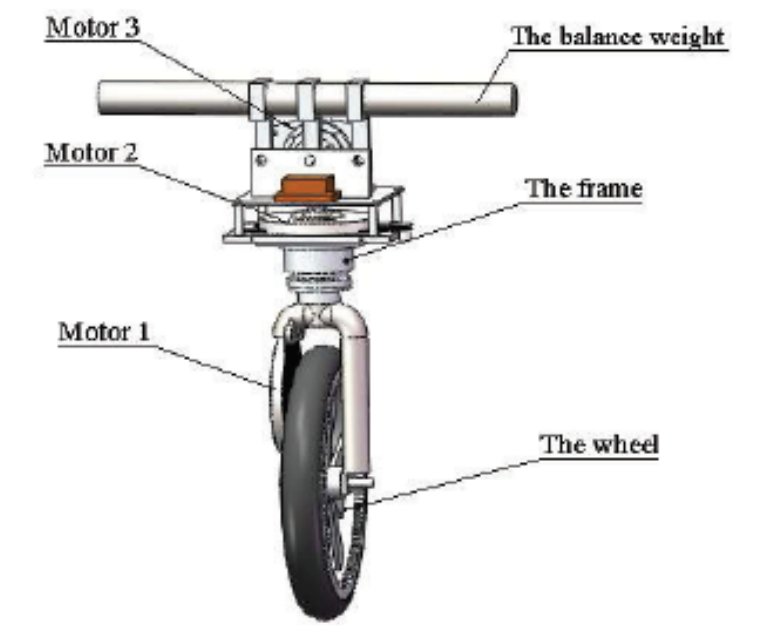

Source: (HU et al., 2014) and (GUO; HE; SONG, 2016).

Figure 4: Example of a unicycle with a gyroscopic system.

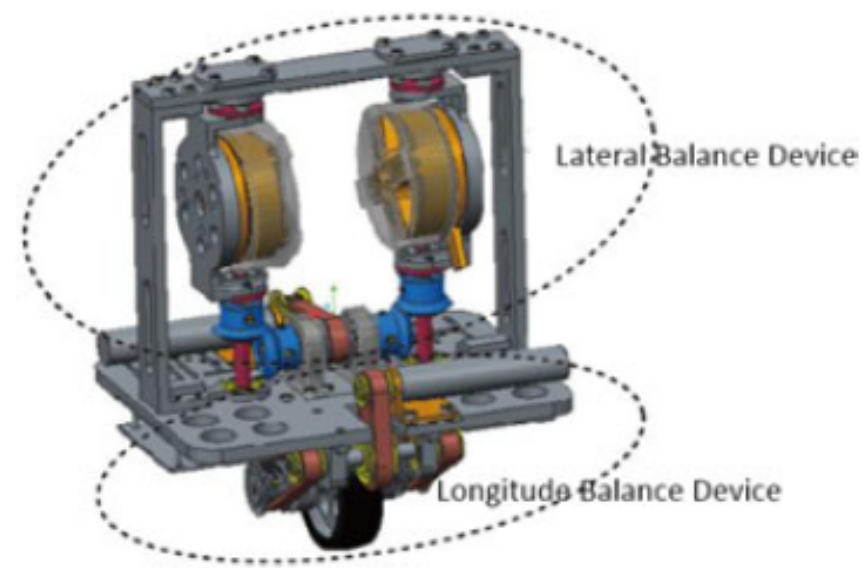

Source: (JIN et al., 2016). 


\section{CONSTRUCTION}

The construction of the prototype is part of this project, and this chapter shows the general idea and the construction of each part of the unicycle.

\subsection{Initial Concept}

The unicycle controlled by reaction wheel consists of three parts, the reaction wheel, the body and the travel wheel, as shown in Figure 5.

Figure 5: Schematic drawing.

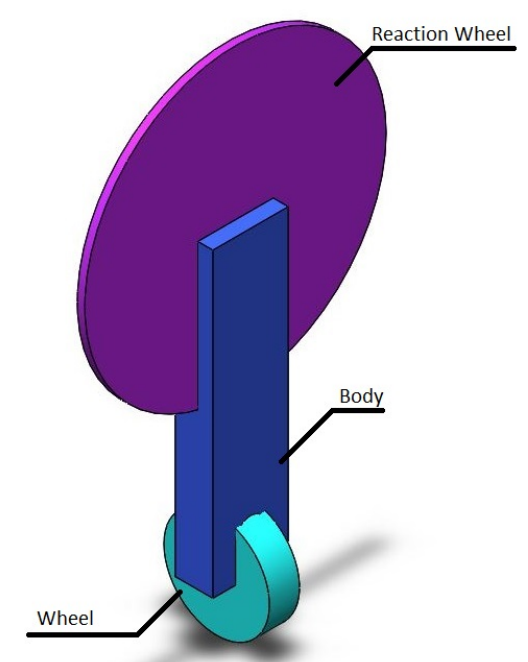

Source: Author.

The reaction wheel is responsible for the roll control and is fixed at the top, and the wheel is responsible for the pitch control, in the lower part. 


\subsection{Body}

The body must attach all the electronic components, a battery and the two wheels, making the unicycle totally autonomous. As is shown in Figure 6a, the reaction wheel is attached to the higher part, and the travel wheel to lower part.

The body is hollow and all the electronic components are fixed into the body channel as shown in the Figure 6b. Lastly, the battery is attached to the opposite side of the wheel motor, such that the system is balanced, that is, the center of mass is nearly to the central axis.

Figure 6: Unicycle body

(a) Front view.

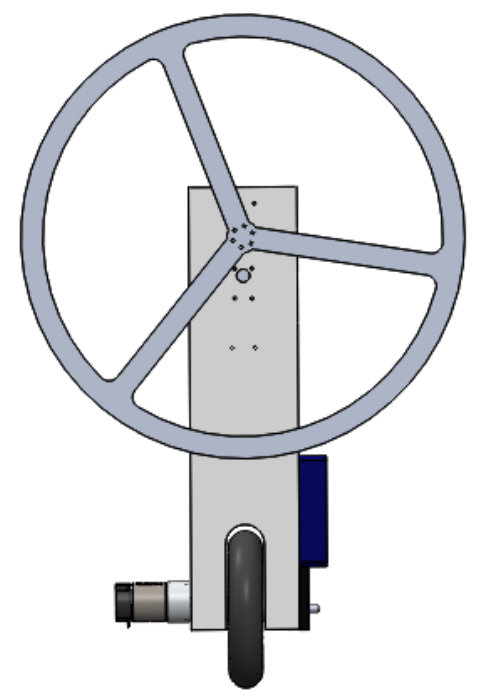

(b) Back view.

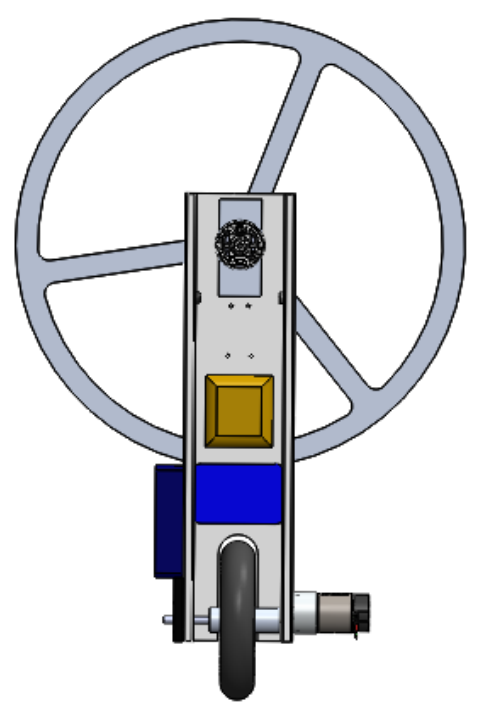

Source: Author

\subsection{Travel Wheel}

This wheel contains two sleeves and one axle is attached to a bearing (fixed to the body). The wheel is attached to the axle, as shown in Figures 7 and 8, respectively. It is important to observe that the wheel has a concave pattern, such that its contact to the ground is similar to a point, making more difficult the lateral balancing control.

\subsection{Reaction Wheel}

The reaction wheel is fixed to the body by the motor. Its geometry is designed to control the unicycle with a viable motor and to keep the system balanced, such that the 
Figure 7: Bearing and Axle.

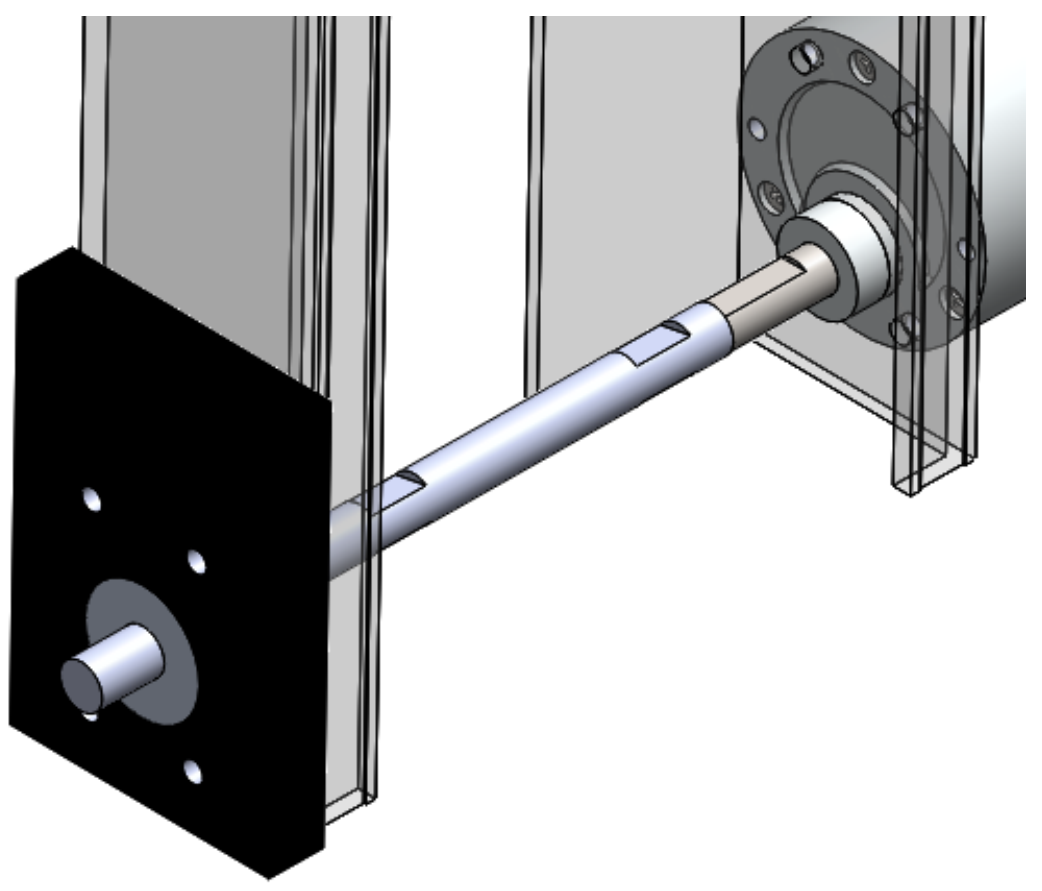

Source: Author.

Figure 8: Unicycle's wheel.

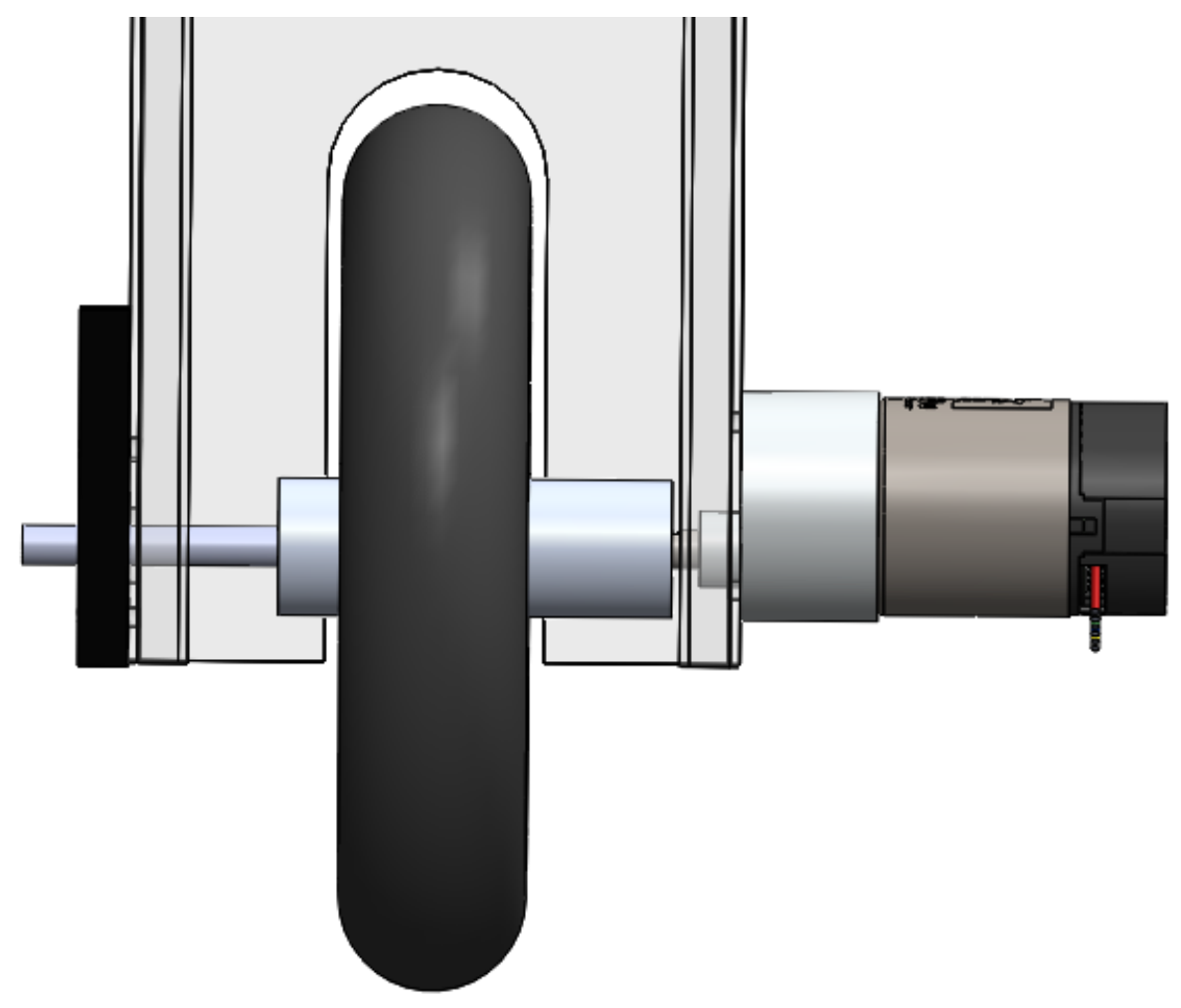

Source: Author.

center of mass is nearly aligned with the contact point of the wheel.

If the travel wheel is stuck, the system can be considered an inverted pendulum with 
Figure 9: Schematic drawing.

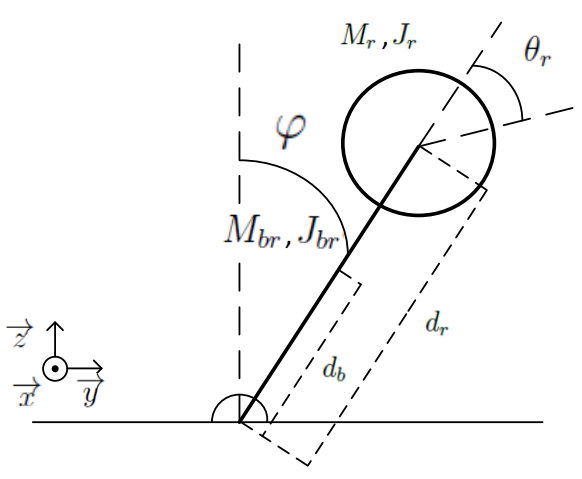

Source: Author.

Figure 10: Free body diagram.

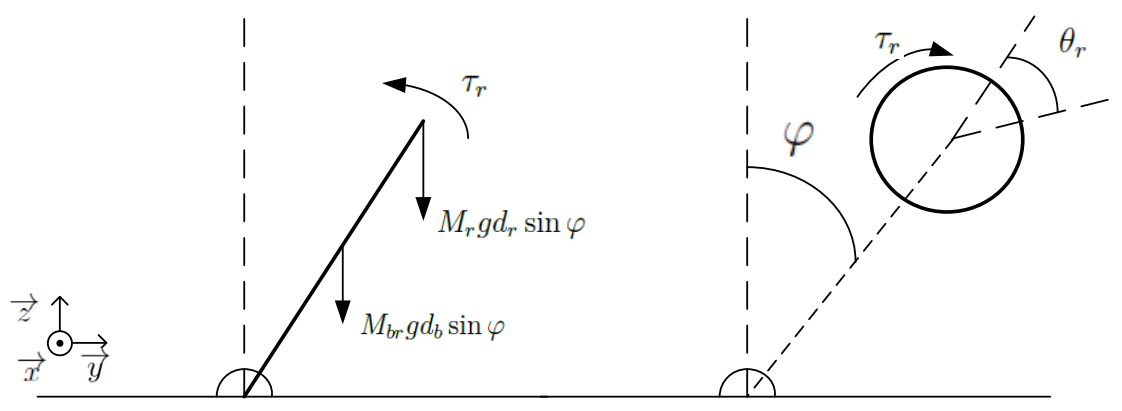

Source: Author.

a reaction wheel. Figure 9 shows the schematic drawing of the inverted pendulum, while Figure 10 shows the free body diagram.

Newton's second law of the pendulum and the reaction wheel are

$$
\begin{array}{r}
\tau_{r}-M_{r} g d_{r} \sin \varphi-M_{b r} g d_{b} \sin \varphi=J_{b r} \ddot{\varphi}, \\
\left(\ddot{\theta_{r}}+\ddot{\varphi}\right) J_{r}=\tau_{r},
\end{array}
$$

where, $M_{r}, J_{r}, d_{r}, M_{b r}, J_{b r}, d_{b}$ are, respectively, the mass of reaction wheel, the moment of inertia of reaction wheel around the center of mass, the distance of the reaction wheel center, the mass of the body, the moment of inertia of the body around the center of mass, and the distance of the pendulum center of mass. In addition, $\varphi$ is the angle of the system with respect to a vertical line, and $\theta_{r}$ is the angle of the reaction wheel.

Thus,

$$
\left(\ddot{\theta_{r}}+\ddot{\varphi}\right) J_{r}-M_{r} g d_{r} \sin \varphi-M_{b r} g d_{b} \sin \varphi=J_{b r} \ddot{\varphi}
$$


so, the linear approximation, considering small angle variation, is

$$
\left(\ddot{\theta}_{r}+\ddot{\varphi}\right) J_{r}-M_{r} g d_{r} \varphi-M_{b r} g d_{b} \varphi=J_{b r} \ddot{\varphi}
$$

So

$$
\ddot{\theta}_{r} J_{r}=\left(J_{b r}-J_{r}\right) \ddot{\varphi}+M_{r} g d_{r} \varphi+M_{b r} g d_{b} \varphi .
$$

The higher the $J_{r}$ the better the control, because, for some applied torque, the angular acceleration will be smaller. On the other hand, the higher the $M_{r}$ the worse the control as can be seen in equation 2.5. In addition, the moment of inertia of a ring $^{1}$ is calculated as

$$
J_{r}=\frac{M_{r}}{2}\left(R_{1}^{2}+R_{2}^{2}\right),
$$

where $R_{1}$ is the internal radius and $R_{2}$ is the external radius, establishing a relation between $J_{r}$ and $M_{r}$. Among the easiest and lightest possible materials, aluminum was chosen to make the reaction wheel. The resulting reaction wheel is shown in Figure 11 and the value of $J_{r}$ and $M_{r}$ can be seen in the Table 1.

Figure 11: Unicycle's reaction wheel.

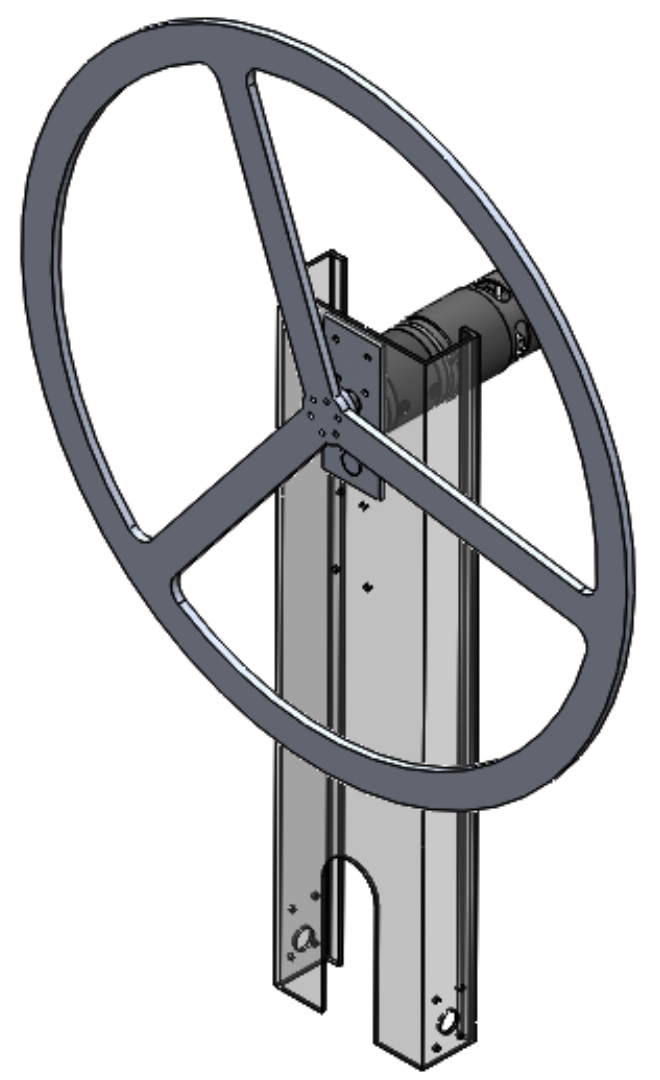

Source: Author.

\footnotetext{
${ }^{1}$ The reaction wheel can be approximated by a ring.
} 


\subsection{Motors}

The Figure 12a shows the reaction wheel motor and Figure $12 \mathrm{~b}$ the travel motor. The specifications of the motors can be seen in Table 1 .

Figure 12: Unicycle motors

(a) Motor of the reaction wheel.

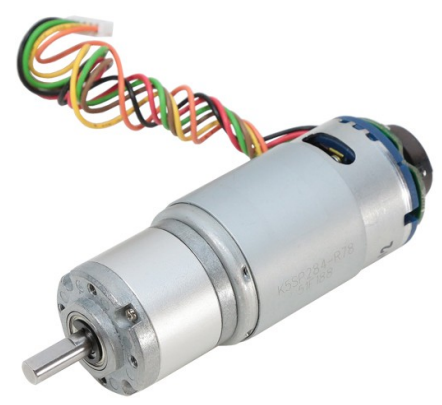

(b) Motor of the wheel.

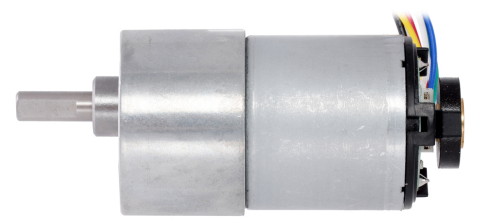

Source:

https://www.servocity.com/118-rpm-hd-premium-planetary-gear-motor-w-encoder and https://www.pololu.com/product/2827

Although the motors have sufficient stall torque for stabilizing the unicycle, the rapid variation in direction along with the high moment of inertia can cause high dynamic torque, which can damage the motor reduction gearbox.

An approximation of the dynamic torque can be calculated by

$$
\tau_{\text {dynamic }}=\frac{|\Delta \omega|}{\Delta t} J
$$

where, $\Delta \omega$ is the angular velocity variation, $J$ is the moment of inertia and $\Delta t$ is the time variation. In the worst case

$$
\tau_{\text {dynamic }}=\frac{2 \omega}{\Delta t} J
$$

where, $\omega$ is the maximum speed of the motor after the gear box. Thus, if the controller change the rotation direction very fast $(\Delta t \rightarrow 0)$, the dynamic torque tends to $\infty$. In order to protect the gearbox, a first order filter is considered

$$
G_{l p f}=\frac{30}{s+30}
$$

where, $s$ is the variable of the Laplace transformation. The time constant of this filter is $\tau_{t}=1 / 30$. Therefore, for a step response, the system will take $4 \tau_{t}$, which is equal to 0.133 second, to reach $98 \%$ of the maximum value. 
Considering the worst case for the reaction wheel motor (maximum speed of $118 \mathrm{rpm}$ ), the dynamic torque is

$$
\tau_{\text {dynamic }}=\frac{2(118 \times 2 \times \pi / 60)}{0.1333} \times 0.013472=2.4971[\mathrm{Nm}],
$$

which is lower than half the stall torque of the motor, thus, the gearbox is protected from overload by the dynamic torque.

\subsection{Physical Parameters}

To write the mathematical model, the physical parameters of the plant are necessary. The mechanical parameters were obtained from the 3D CAD model built in SolidWorks. The viscous friction coefficients were estimated from experimental tests, while the motor parameters are obtained from the motors datasheets. Table 1 shows all the parameters and their values.

Table 1: Physical Parameters

\begin{tabular}{|c|c|c|}
\hline & Parameter & Value \\
\hline$R_{r}$ & Reaction wheel radius $[m]$ & 0.2 \\
\hline$R_{w}$ & Wheel radius $[\mathrm{m}]$ & 0.071 \\
\hline$L$ & Distance of the center of mass $(\mathrm{CM})$ of the body $[\mathrm{m}]$ & 0.18632 \\
\hline$d$ & Distance between the CM of the body and reaction wheel $[\mathrm{m}]$ & 0.1503 \\
\hline$M_{r}$ & Reaction wheel mass $[K g]$ & 0.47568 \\
\hline$M_{b}$ & Body mass $[K g]$ & 1.23913 \\
\hline$M_{w}$ & Wheel mass $[K g]$ & 0.30220 \\
\hline$g$ & Acceleration of gravity $\left[\mathrm{m} / \mathrm{s}^{2}\right]$ & 9.8 \\
\hline$J_{r}$ & Reaction wheel moment of inertia $\left[\mathrm{Kgm}^{2}\right]$ & 0.013472 \\
\hline$J_{w}$ & Wheel moment of inertia $\left[\mathrm{Kgm}^{2}\right]$ & 0.00077 \\
\hline$J_{b r}$ & Moment of inertia of the body plus reaction wheel $\left[\mathrm{Kgm}^{2}\right]$ & 0.03937 \\
\hline$J_{b w}$ & Moment of inertia of the body plus wheel $\left[\mathrm{Kgm}^{2}\right]$ & 0.03458 \\
\hline$n_{r}$ & Reduction of the reaction wheel motor & 71 \\
\hline$K_{t r}$ & Torque constant of the reaction wheel motor $[\mathrm{Nm} / \mathrm{A}]$ & 0.3383 \\
\hline$K_{e r}$ & Electrical constant of the reaction wheel motor $\left[\mathrm{Vs}^{2} / \mathrm{rad}\right]$ & 0.9454 \\
\hline$R_{e r}$ & Electrical resistance of the reaction wheel motor $[\Omega]$ & 0.6 \\
\hline$n_{w}$ & Reduction of the wheel motor & 131.25 \\
\hline$K_{t w}$ & Torque constant of the wheel motor $[\mathrm{Nm} / \mathrm{A}]$ & 0.3531 \\
\hline$K_{e w}$ & Electrical constant of the reaction wheel motor $\left[\mathrm{Vs}^{2} / \mathrm{rad}\right]$ & 1.3465 \\
\hline$R_{e w}$ & Electrical resistance of the wheel motor $[\Omega]$ & 2.4 \\
\hline$B_{v w}$ & Travel wheel viscous friction $\left[N s^{2} / \mathrm{rad}\right]$ & 0.1 \\
\hline$B_{v r}$ & Reaction wheel viscous friction $\left[\mathrm{Ns}^{2} / \mathrm{rad}\right]$ & 0.1 \\
\hline
\end{tabular}

The motors constants shown in Table $1\left(K_{t r}, K_{e r}, K_{t w}, K_{e w}\right)$, are presented considering 
torque and speed after the reduction (in gearbox shaft).

\subsection{Electric Circuit}

The electronic system consist of two motor drivers, Inertial Measurement Unit (IMU) sensor, a microcontroller and a circuit board used for integrating all the parts. Figure 13 presents the microcontroller (K64F).

Figure 13: Microcontroller.

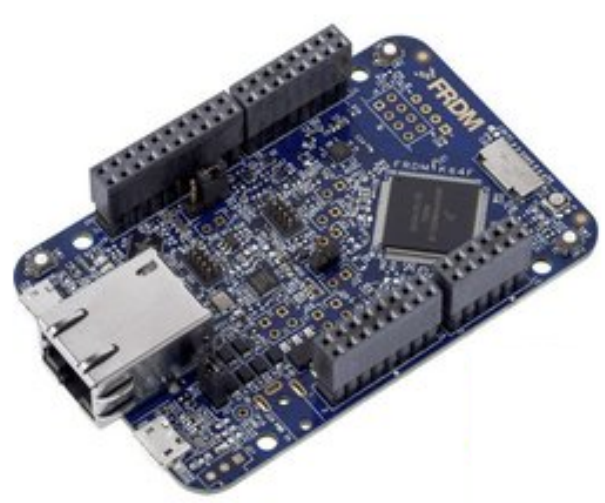

Source: https://developer.mbed.org/platforms/FRDM-K64F/

Figure 14 shows the position of all electronic components. The ideal is to fix the circuit board (with the IMU welded) at the center of mass of the unicycle.

\subsubsection{Motor Drive}

Each motor has a $\mathrm{H}$ bridge driver, and the voltage in the terminal is controlled by a $P W M$ signal.

The driver used is the VNH3SP30, shown in Figure 15. The rotation direction is controlled by inputs INA and INB. The $P W M$ signal is limited to a frequency up to 10 KHz. Table 2 shows the driver operation, where, $V_{\text {out }}$ and $V_{c c}$ are the output ${ }^{2}$ and input voltage, respectively.

\subsubsection{Inertial Measurement Unit}

The pitch and roll angle are measured using an IMU. In this project, the GY-86, presented in Figure 16, is used. The angles are estimated by the sensor fusion of the

\footnotetext{
${ }^{2}$ The output voltage is approximately the PWM times the input voltage.
} 
Figure 14: Schematic drawing of electronic components arrangement.

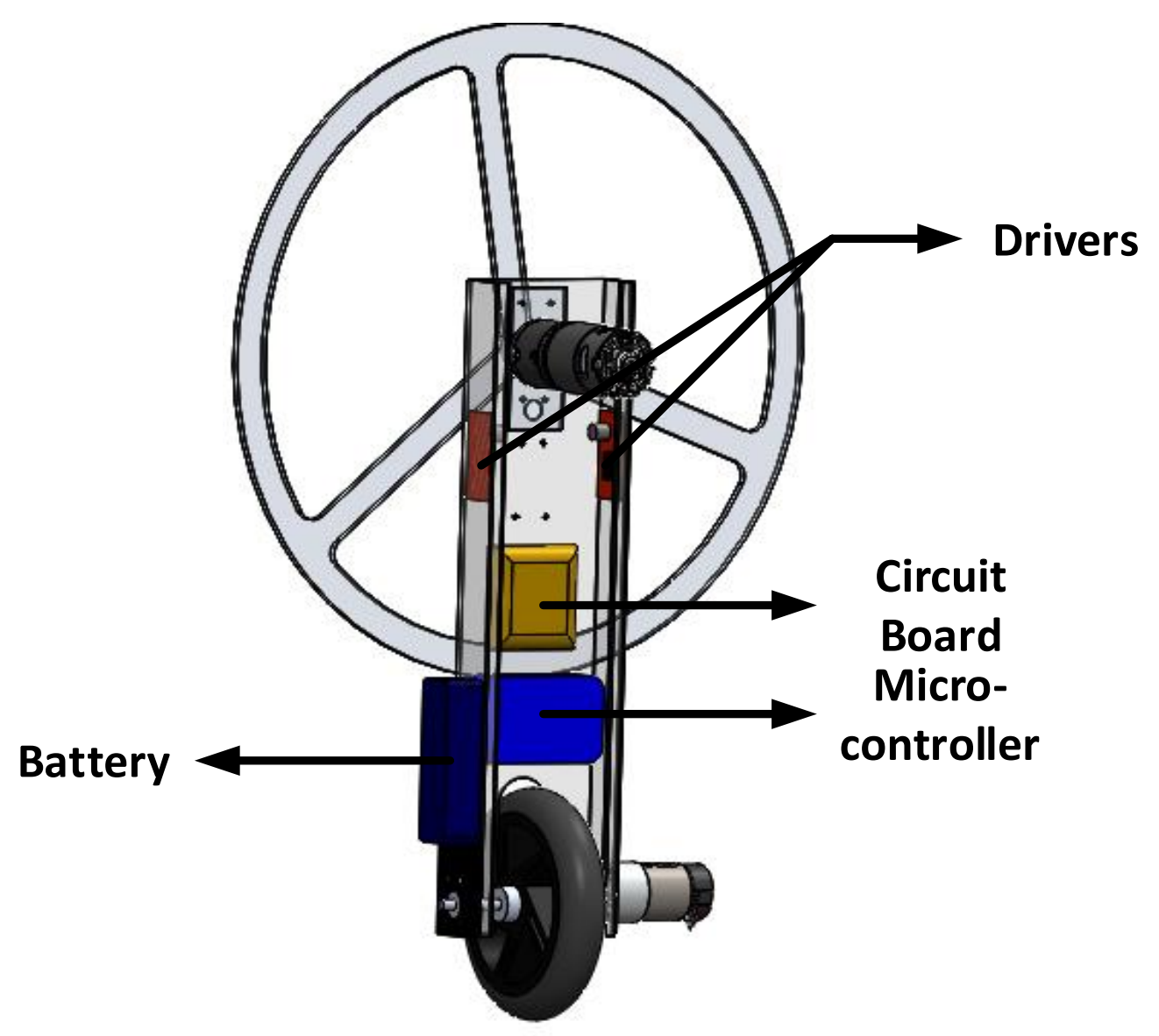

Source: Author

Figure 15: Motor driver.

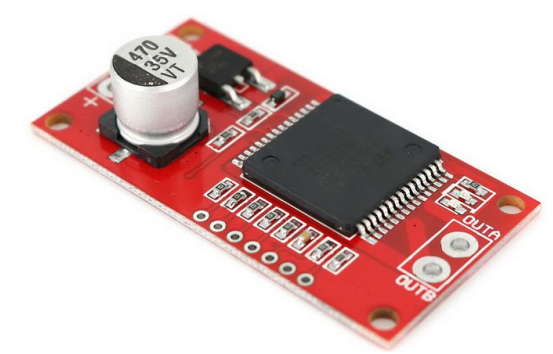

Source: http://www.dx.com/

accelerometer and the gyroscope, considering a Kalman filter (FRANKLIN; POWELL; WORKMAN, 2006).

The pitch angle $(\psi)$ and the roll angle $(\varphi)$ can be calculated by the accelerometer measurement 
Table 2: Drive operation

\begin{tabular}{r|r|r|r|l}
$I N_{A}$ & $I N_{B}$ & $O U T_{A}$ & $O U T_{B}$ & Comment \\
\hline 0 & 0 & 0 & 0 & Brake to GND \\
0 & 1 & 0 & $V_{\text {out }}$ & Clockwise \\
1 & 0 & $V_{\text {out }}$ & 0 & Counter Clockwise \\
1 & 1 & $V_{\text {out }}$ & $V_{\text {out }}$ & Brake to $V_{c c}$
\end{tabular}

Figure 16: IMU Sensor.
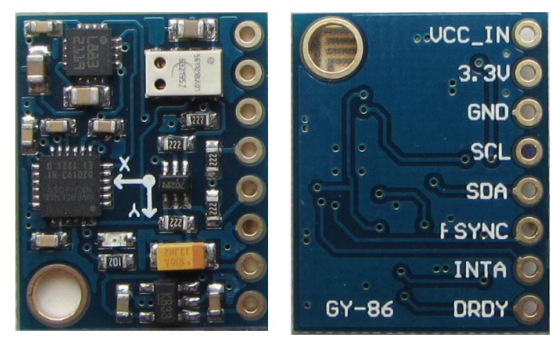

Source: https://pt.aliexpress.com/store/

$$
\begin{gathered}
\hat{\varphi}_{k}=\operatorname{atan} 2\left(a_{z}, \sqrt{a_{y}^{2}+a_{x}^{2}}\right), \\
\hat{\psi}_{k}=\operatorname{atan} 2\left(-a_{x}, \sqrt{a_{y}^{2}+a_{z}^{2}}\right),
\end{gathered}
$$

where, $a_{x}, a_{y}$ and $a_{z}$ are the acceleration in directions $\vec{x}, \vec{y}$ and $\vec{z}$ respectively.

The Kalman filter algorithm is the same for $\varphi$ and $\psi$. Considering only $\varphi$ the angle update, by means of the gyroscope dynamics, it is given by

$$
\varphi_{k}^{-}=\varphi_{k-1}+\left(\varphi_{\text {gyro }}-\varphi_{\text {bias }}\right) T s,
$$

where, $\varphi_{k}^{-}$is the angle calculated by the gyroscope measurement, $\varphi_{k-1}$ is the value of the angle in the previous interaction, $\varphi_{\text {gyro }}$ is the measurement of the gyroscope, $T s$ is the sample time and $\varphi_{\text {bias }}$ is the bias.

The estimation error covariance is

$$
P_{k}^{-}=\left[\begin{array}{cc}
1 & -T s \\
0 & 1
\end{array}\right] P_{k-1}\left[\begin{array}{cc}
1 & 0 \\
-T s & 1
\end{array}\right]+Q T s,
$$

where $Q$ is the process noise covariance.

The Kalman gain, the measurement update and the covariance error are given by 


$$
\begin{aligned}
K_{k} & =P_{k}^{-} H^{\top}\left(H P_{k}^{-} H^{\top}+R\right)^{-1}, \\
{\left[\begin{array}{c}
\varphi_{k} \\
\varphi_{\text {bias }}
\end{array}\right] } & =\left[\begin{array}{c}
\varphi_{k}^{-} \\
\varphi_{\text {bias }}^{-}
\end{array}\right]+K_{k}\left(\hat{\varphi}_{k}-\varphi_{k}^{-}\right), \\
P_{k} & =\left(I-K_{k} H\right) P_{k}^{-},
\end{aligned}
$$

where $R$ is the measurement covariance noise and $H=\left[\begin{array}{ll}1 & 0\end{array}\right]$. In this project

$$
Q=\left[\begin{array}{cc}
0.001 & 0 \\
0 & 0.003
\end{array}\right]
$$

and

$$
R=0.03
$$

\subsection{Unicycle built}

With the integration of the mechanical and electrical parts, the schematic drawing and the real plant are presented in Figures 17 and 18 respectively.

Figure 17: Schematic drawing

(a) View 1.

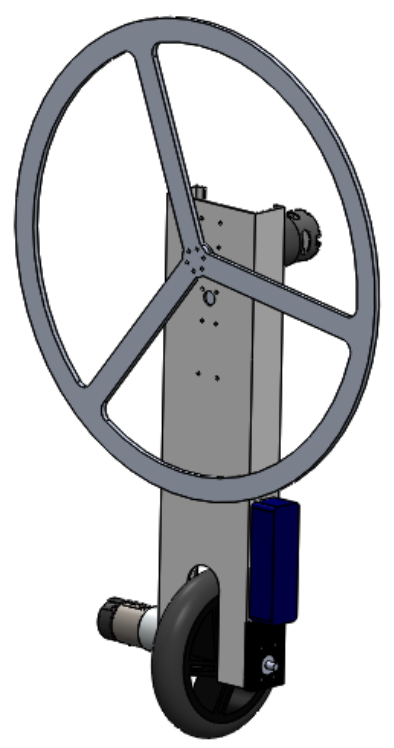

(b) View 2 .

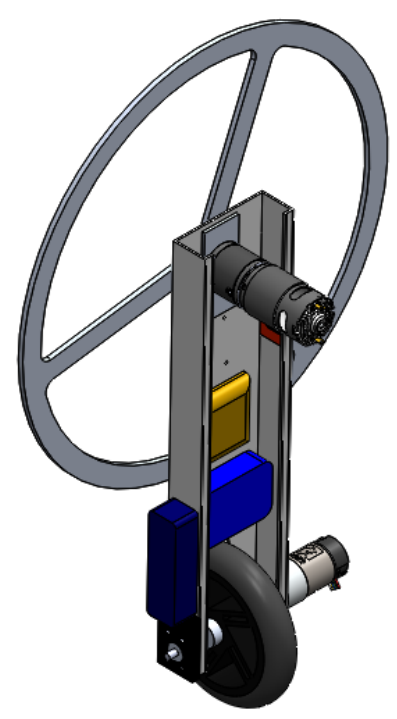

Source: Author 
Figure 18: Practical unicycle

(a) View 1.

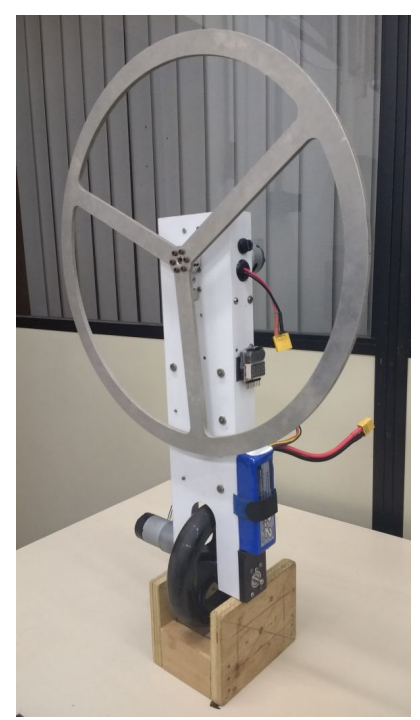

(b) View 2

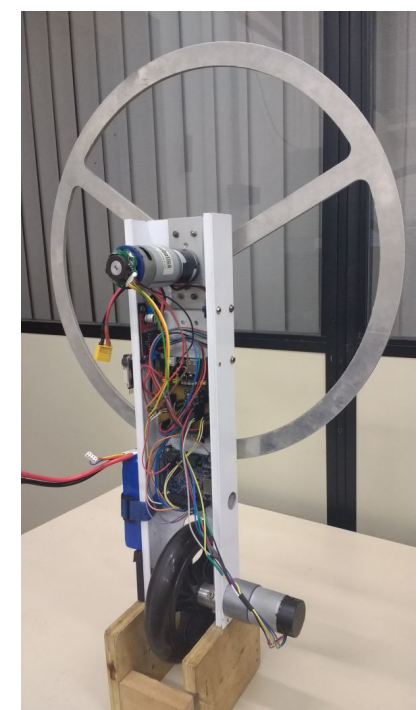

Source: Author 


\section{SYSTEM MODELING}

In this chapter the mathematic model of the system is developed.

\subsection{Non-Linear Model}

This section details the complete non-linear model.

\subsubsection{Position of the Unicycle}

As shown in Chapter 2, the unicycle has three parts, theirs center of mass are determined by $\overrightarrow{p_{1}}, \overrightarrow{p_{2}}$ and $\overrightarrow{p_{3}}$ respectively for the position of the travel wheel, body and reaction wheel (HAN; LEE, 2015). Furthermore, the unicycle is considered to be positioned on the $\vec{x}$ axis, as shown in Figure 19 .

The wheel is assumed not to slip, hence, the projection of $\overrightarrow{p_{1}}$ on the $\vec{x}$ is $R_{w} \theta_{w}$. The projection of $\overrightarrow{p_{1}}$ on the $y z$ plane is shown in Figure 20, and the norm of this projection is the travel wheel radius $\left(R_{w}\right)$.

Thus, the position vector $\overrightarrow{p_{1}}$ can be written as

$$
\overrightarrow{p_{1}}=\left[\begin{array}{lll}
R_{w} \theta_{w} & R_{w} \sin (\varphi) & R_{w} \cos (\varphi)
\end{array}\right]
$$

The vector $\overrightarrow{p_{2}}$, the position of body center of mass, can be written as the sum of $\overrightarrow{p_{1}}$ and $\overrightarrow{p_{L}}$ (a vector with origin at the travel wheel center of mass and the extremity at the body center of mass), as shown in Figure 21. Hence, the projection of $\overrightarrow{p_{2}}$ on the $\vec{x}$ axis is the sum of the projections of $\overrightarrow{p_{1}}$ and $\overrightarrow{p_{L}}$. Therefore,

$$
\operatorname{proj}_{\vec{x}} \overrightarrow{p_{2}}=\operatorname{proj}_{\vec{x}} \overrightarrow{p_{1}}+\operatorname{proj}_{\vec{x}} \overrightarrow{p_{L}}
$$

then,

$$
\operatorname{proj}_{\vec{x}} \overrightarrow{p_{2}}=R_{w} \theta_{w}+L \sin (\psi)
$$


Figure 19: Positions of the bodies.

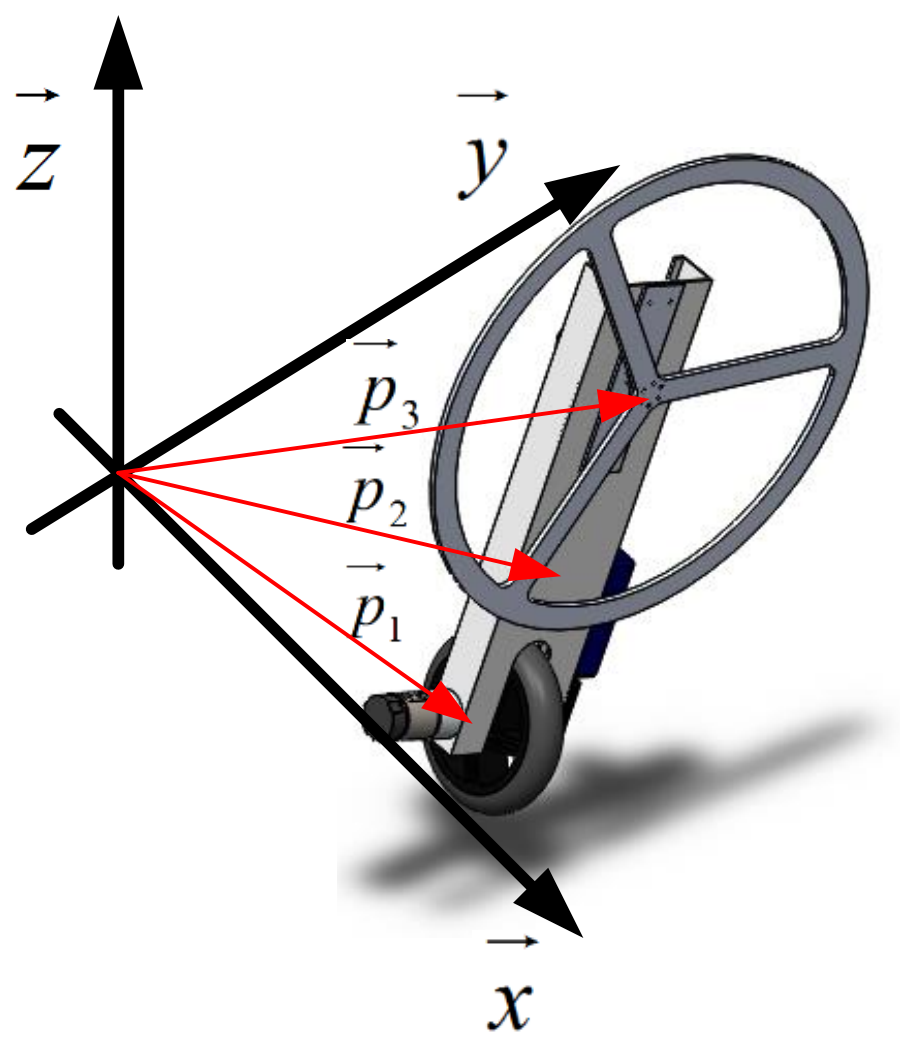

Source: Author.

Figure 20: Projection of $\overrightarrow{p_{1}}$ on the $y z$ plane.

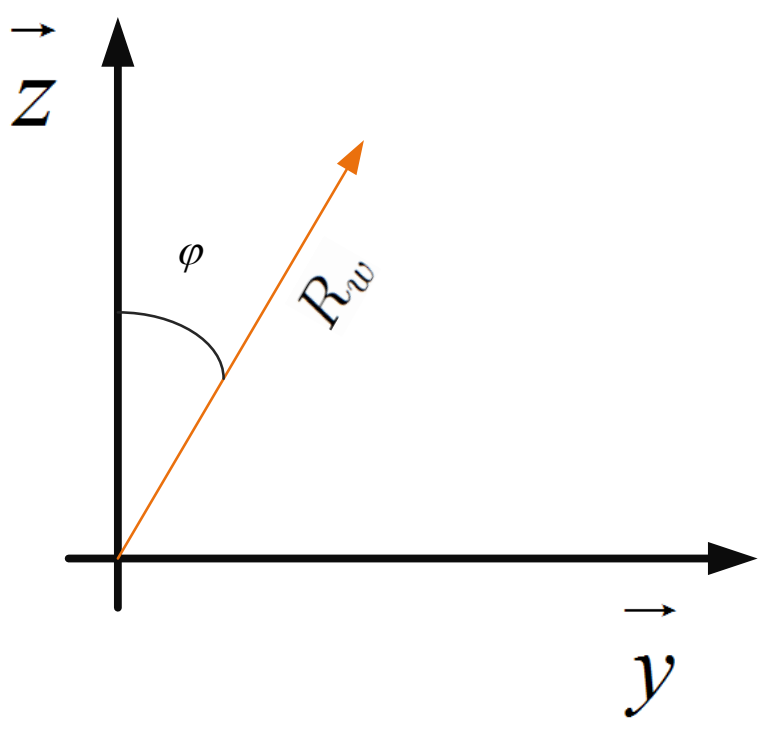

Source: Author. 
Figure 21: Position Vector $\overrightarrow{p_{2}}$.

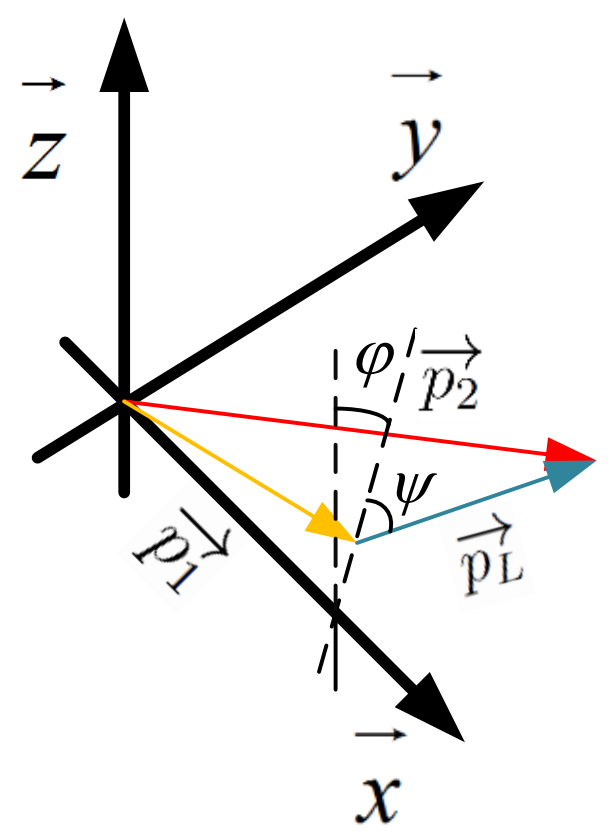

Source: Author.

Similarly to the projection on the $\vec{x}$ axis, the projection of $\overrightarrow{p_{2}}$ on the $y z$ plane is the sum of projection of $\overrightarrow{p_{1}}$ and $\overrightarrow{p_{L}}$, as is shown in Figure 22. So, the projection of $\overrightarrow{p_{2}}$ on $\vec{y}$ and $\vec{z}$ are

$$
\operatorname{proj}_{\vec{z}} \overrightarrow{p_{2}}=R_{w} \cos (\varphi)+L \cos (\psi) \cos (\varphi),
$$

and

$$
\operatorname{proj}_{\vec{y}} \overrightarrow{p_{2}}=R_{w} \sin (\varphi)+L \cos (\psi) \sin (\varphi) .
$$

Therefore, vector $\overrightarrow{p_{2}}$ is written as

$$
\overrightarrow{p_{2}}=\left[\begin{array}{lll}
R_{w} \theta_{w}+L \sin (\psi) & \left(R_{w}+L \cos (\psi)\right) \sin (\varphi) \quad\left(R_{w}+L \cos (\psi)\right) \cos (\varphi)
\end{array}\right] .
$$

Vector $\overrightarrow{p_{3}}$ can be described as the sum of $\overrightarrow{p_{1}}$ and $\overrightarrow{p_{d}}$, where $\overrightarrow{p_{d}}$ is a vector with originat the body center of mass and the extremity at the reaction wheel center of mass $\left(\left\|\overrightarrow{p_{d}}\right\|=L+d\right)$, as is shown in Figure 23 . 
Figure 22: Projection of $\overrightarrow{p_{2}}$ on the $y z$ plane.

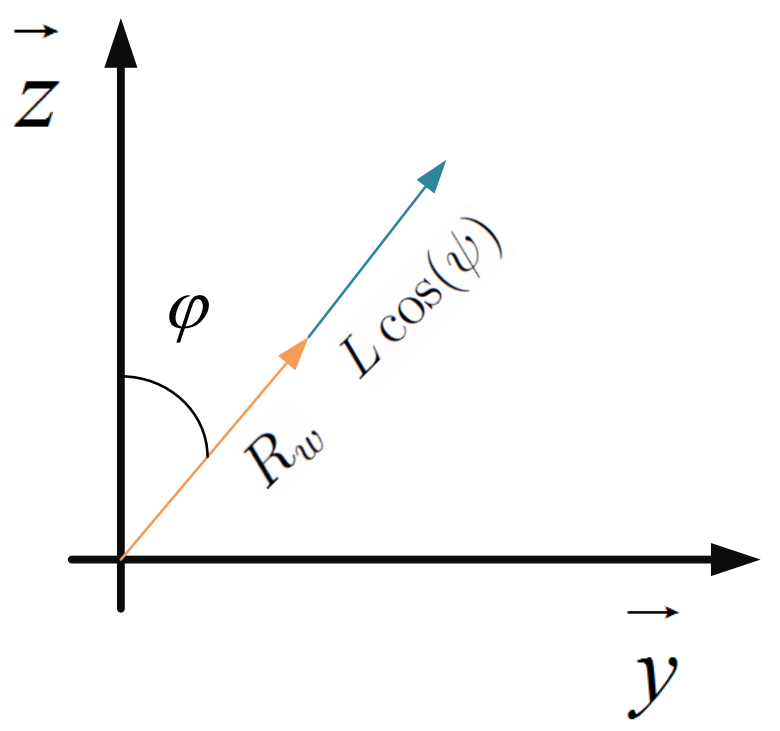

Source: Author.

Figure 23: Position Vector $\overrightarrow{p_{3}}$.

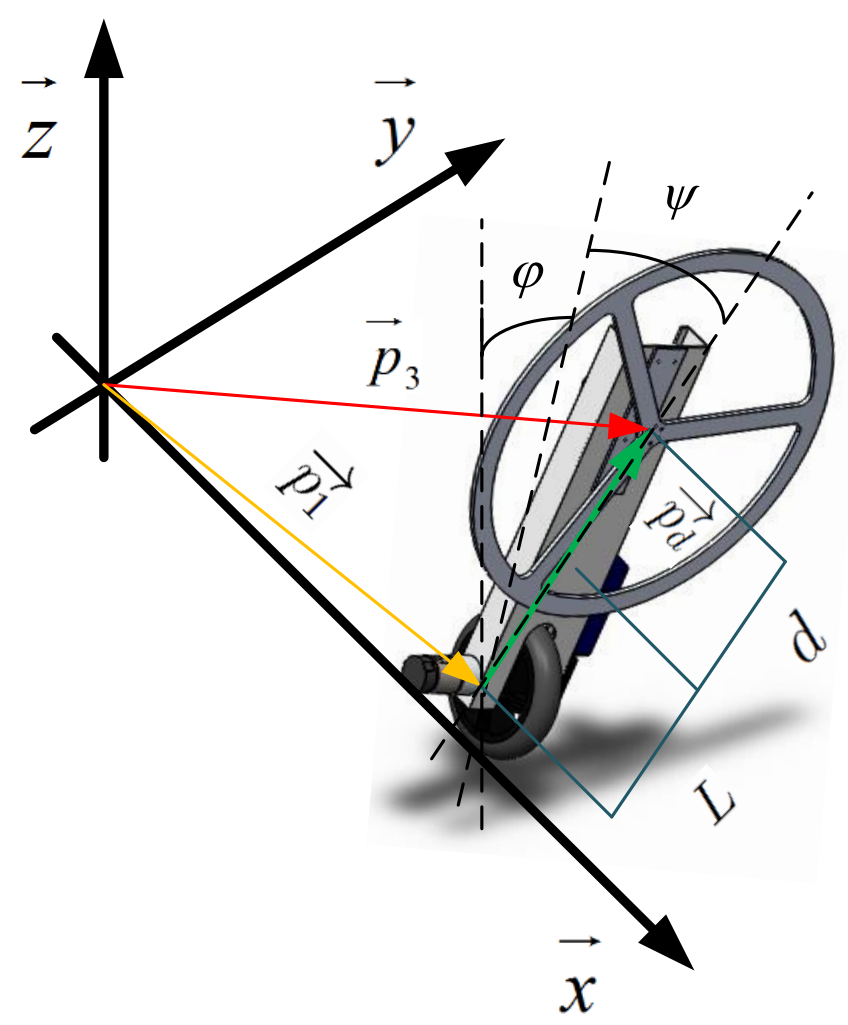

Source: Author. 
In the same way as $\overrightarrow{p_{2}}, \overrightarrow{p_{3}}$ can be written as

$$
\overrightarrow{p_{3}}=\left[\begin{array}{lll}
R_{w} \theta_{w}+(L+d) \sin (\psi) & \left.\left(R_{w}+(L+d) \cos (\psi)\right) \sin (\varphi) \quad\left(R_{w}+(L+d) \cos (\psi)\right) \cos (\varphi)\right]
\end{array}\right.
$$

\subsubsection{Energy Calculation}

The translational kinetic energy is calculated by

$$
E_{T}=\frac{1}{2} \vec{v}^{\top} M \vec{v}
$$

where $M$ is the mass of the object and $\vec{v}$ is the velocity vector of the center of mass in relation to the inertial system. Thus, the translational kinetic energy of the unicycle is given by

$$
E_{T}=\frac{1}{2}{\overrightarrow{v_{1}}}^{\top} M_{w} \overrightarrow{v_{1}}+\frac{1}{2}{\overrightarrow{v_{2}}}^{\top} M_{b}{\overrightarrow{v_{2}}}+\frac{1}{2}{\overrightarrow{v_{3}}}^{\top} M_{r} \overrightarrow{v_{3}}
$$

where,

$$
\begin{aligned}
& \overrightarrow{v_{1}}=\frac{d}{d t} \overrightarrow{p_{1}} \\
& \overrightarrow{v_{2}}=\frac{d}{d t} \overrightarrow{p_{2}} \\
& \overrightarrow{v_{3}}=\frac{d}{d t} \overrightarrow{p_{3}}
\end{aligned}
$$

The rotational kinetic energy is calculated as

$$
E_{R}=\underbrace{\frac{1}{2} J_{w} \dot{\theta}_{w}^{2}}_{1}+\underbrace{\frac{1}{2} J_{b r} \dot{\psi}^{2}}_{2}+\underbrace{\frac{1}{2} J_{r}\left(\dot{\theta}_{r}+\dot{\varphi}\right)^{2}}_{3}+\underbrace{\frac{1}{2} J_{b w} \dot{\varphi}^{2}}_{4},
$$

where, part 1 of the equation corresponds to the travel wheel rotation, part 2 is the rotation of the pitch angle, part 3 corresponds to the rotation of the reaction wheel and its center of mass, part 4 is the rotation of the roll angle.

The potential energy of a body with mass $M$ and height of its center of mass in relation to a reference plane given by $h$ is calculated as

$$
U=M g h
$$

In this problem, the ground is considered to be the reference plane, the height is the projection of vectors $\overrightarrow{p_{1}}, \overrightarrow{p_{2}}$ and $\overrightarrow{p_{3}}$ on the $\vec{z}$ axis, hence, the potential energy of the 
unicycle is calculated as

$$
U=M_{w} g R_{w} \cos (\varphi)+M_{b} g\left(\left(R_{w}+L \cos (\psi)\right) \cos (\varphi)\right)+M_{r} g\left(R_{w}+(L+d) \cos (\psi)\right) \cos (\varphi)
$$

\subsubsection{Lagrange Equation}

The Lagrange equation is used to determine the dynamic model of the system (CRAIG, 2005). The Lagrangian is defined as

$$
L=E_{T}+E_{R}-U
$$

where, $E_{T}, E_{w}$ and $U$ are the translational kinetic energy, rotational kinetic energy and the potential energy, respectively.

Given $q=\left[\begin{array}{llll}\theta_{r} & \varphi & \theta_{w} & \psi\end{array}\right]^{\top}$ (vector of the variables corresponding to the degrees of freedom), and $\tau$ the vector of external torques and force, the Lagrange equation is written as

$$
\frac{d}{d t} \frac{\partial L}{\partial \dot{q}}-\frac{\partial L}{\partial q}=\tau-B_{v}
$$

where $B_{v}=\left[\begin{array}{llll}B_{v r} \theta_{r} & -B_{v r} \theta_{r} & B_{v w} \theta_{w} & -B_{v w} \theta_{w}\end{array}\right]^{\top}$ is the vector of the viscous friction.

In this case, the external torque is caused by the motors and their reactions, such that

$$
\tau=\left[\begin{array}{llll}
\tau_{r} & -\tau_{r} & \tau_{w} & -\tau_{w}
\end{array}\right]^{\top}
$$

where, $\tau_{r}$ is the torque caused by the motor connected to the reaction wheel, and $\tau_{w}$ the torque caused by the motor connected to the travel wheel. The equations of the DC motors are

$$
\begin{aligned}
\tau_{r} & =\frac{n_{r} K_{t r}}{R_{e r}}\left(12 P W M_{r}-K_{e r} n_{r} \dot{\theta_{r}}\right), \\
\tau_{w} & =\frac{n_{w} K_{t w}}{R_{e w}}\left(12 P W M_{w}-K_{e w}\left(n_{w} \dot{\theta_{w}}-\dot{\psi}\right)\right),
\end{aligned}
$$

where, $P W M_{r}$ and $P W M_{w}$ are the $P W M$ of the motor coupled with the reaction wheel and the travel wheel, respectively. It is worth mentioning, as was said in Chapter 2, that the motor constants are considered after the reduction, hence, in equations (3.19) and (3.20) $n_{r}=1$ and $n_{w}=1$

From the Lagrange equation and the input vector $u=\left[\begin{array}{ll}P W M_{r} & P W M_{w}\end{array}\right]^{\top}$, the non- 
linear model can be written as

$$
M(q) \ddot{q}+V(q, \dot{q})+G(q)=P u
$$

where,

$$
\begin{gathered}
M(q)=\left[\begin{array}{cccc}
M_{11} & M_{12} & 0 & 0 \\
M_{21} & M_{22} & 0 & 0 \\
0 & 0 & M_{33} & M_{34} \\
0 & 0 & M_{43} & M_{44}
\end{array}\right] \\
V(q, \dot{q})=\left[\begin{array}{c}
V_{1} \\
V_{2} \\
V_{3} \\
V_{4}
\end{array}\right] \\
G(q)=\left[\begin{array}{c}
0 \\
G_{2} \\
0 \\
G_{4}
\end{array}\right]
\end{gathered}
$$

and

$$
P=\left[\begin{array}{cc}
\frac{12 K_{t r} n_{r}}{R_{r}} & 0 \\
\frac{-12 K_{t r} n_{r}}{R_{r}} & 0 \\
0 & \frac{12 K_{t w} n_{w}}{R_{w}} \\
0 & \frac{-12 K_{t w} n_{w}}{R_{w}}
\end{array}\right]
$$

The terms of the matrices can be seen in the Appendix A.

\subsection{Linear Model}

This section deals with the linear model, which is obtained for designing linear control techniques. Furthermore, for small variations of the equilibrium point, the system can be approximately linear. 


\subsubsection{Jacobian}

The non-linear system can be rewritten by isolating the second derivative of vector $q$ in equation (3.21), such that

$$
\ddot{q}=M(q)^{-1}(-N(q, \dot{q})-O(q)+P u) .
$$

Equation (3.26) has the form

$$
\ddot{q}=f(q, \dot{q})+b(q) u,
$$

where, $f(q, \dot{q})=-M(q)^{-1}(N(q, \dot{q})+O(q))$ and $b(q)=M(q)^{-1} P$.

In order to simplify the analysis, the state vector $\left[\begin{array}{ll}q & \dot{q}\end{array}\right]^{\top}$ is rearranged as

$$
x=\left[\begin{array}{llllllll}
\theta_{r} & \dot{\theta_{r}} & \varphi & \dot{\varphi} & \theta_{w} & \dot{\theta_{w}} & \psi & \dot{\psi}
\end{array}\right]^{\top},
$$

Thus, the first four terms of $x$ are directly related to the roll angle, and the last four to the pitch angle. The non-linear model considering the state vector $x$ is

$$
\dot{x}=g(x)+h(x) u,
$$

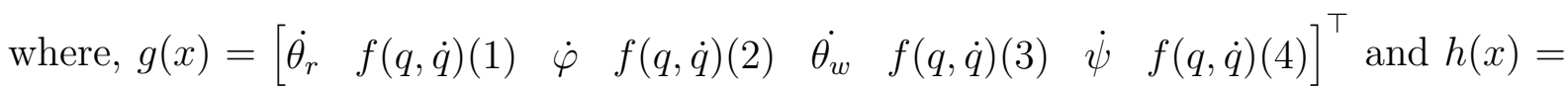
$\left[\begin{array}{llllllll}0 & b(q)(1) & 0 & b(q)(2) & 0 & b(q)(3) & 0 & b(q)(4)\end{array}\right]^{\top}$.

In order to determine the approximated linear model, it is necessary to define the operation point (OP). In the unicycle problem, the $\mathrm{OP}$ is the position of equilibrium in the vertical axis, such that

$$
x_{O P}=\left[\begin{array}{l}
0 \\
0 \\
0 \\
0 \\
0 \\
0 \\
0 \\
0
\end{array}\right], u_{O P}=\left[\begin{array}{l}
0 \\
0
\end{array}\right] .
$$

The linear model, can be written in the space-state model as

$$
\begin{aligned}
\dot{x} & =A x+B u \\
y & =C x,
\end{aligned}
$$


where matrices $A$ and $B$ are obtained by the Jacobian of $g(x)$ with respect to $x$ and $h(x) u$ with respect to $u$. Hence,

$$
\begin{aligned}
& A=\left[\partial g_{i} / \partial x_{j}\right]_{x_{O P}, u_{O P}},(1 \leq i \leq 8 ; 1 \leq j \leq 8) \\
& B=\left[\partial h u_{i} / \partial u_{j}\right]_{x_{O P}, u_{O P}},(1 \leq i \leq 8 ; 1 \leq j \leq 2)
\end{aligned}
$$

and the matrix $C$ is equal the identity matrix $8 \times 8$, because all state variables are measured by the sensors, or estimated, such as the wheels speeds.

Numeric matrices $A$ and $B$, with the parameter of Table I, are

$$
\begin{aligned}
A & =\left[\begin{array}{cccccccc}
0 & 1.0000 & 0 & 0 & 0 & 0 & 0 & 0 \\
0 & -52.1139 & -21.9599 & 0 & 0 & 0 & 0 & 0 \\
0 & 0 & 0 & 1.0000 & 0 & 0 & 0 & 0 \\
0 & 5.1226 & 21.9599 & 0 & 0 & 0 & 0 & 0 \\
0 & 0 & 0 & 0 & 0 & 1.0000 & 0 & 0 \\
0 & 0 & 0 & 0 & 0 & -67.5793 & -151.8787 & 44.9081 \\
0 & 0 & 0 & 0 & 0 & 0 & 0 & 1.0000 \\
0 & 0 & 0 & 0 & 0 & 15.6751 & 58.3574 & -10.4165
\end{array}\right], \\
B & =\left[\begin{array}{cc}
0 & 0 \\
557.0062 & 0 \\
0 & 0 \\
-54.7512 & 0 \\
0 & 0 \\
0 & 400.2352 \\
0 & 0 \\
0 & -92.8352
\end{array}\right] .
\end{aligned}
$$

As the project objective is balance the unicycle, the states $\theta_{r}$ and $\theta_{w}$ can be removed. Thus, the lines and column with indexes one and five are removed. 


\subsection{Linear Model Analysis}

The linear model presents the characteristics of the system around the operation point. The first point that can be observed is the uncoupled characteristic

$$
\begin{aligned}
A & =\left[\begin{array}{cc}
A_{r} & 0 \\
0 & A_{w}
\end{array}\right], \\
B & =\left[\begin{array}{cc}
B_{r} & 0 \\
0 & B_{w}
\end{array}\right],
\end{aligned}
$$

which results in

$$
G=\left[\begin{array}{cc}
G_{r} & 0 \\
0 & G_{w}
\end{array}\right]
$$

As verified, the pitch and roll angle are uncoupled, in other words, $\left[\begin{array}{llll}\varphi & \dot{\varphi} & \dot{\theta}_{r} & \tau_{r}\end{array}\right]$ does not interfere in $\left[\begin{array}{llll}\psi & \dot{\psi} & \dot{\theta_{w}} & \tau_{w}\end{array}\right]$ and vice versa.

\subsubsection{Stability}

A system is stable if all its eigenvalues have negative real parts. The eigenvalues of a continuous multi-variable system are calculated by the eigenvalues of matrix $A$, hence, $\lambda$ is the root of

$$
\operatorname{det}(\lambda I-A)=0
$$

then, the eigenvalues are

$$
\lambda=\left[\begin{array}{llllll}
-79.8373 & -55.4219 & -5.0126 & -4.3996 & 5.0953 & 4.9063
\end{array}\right] .
$$

As observed, the system is unstable, because there are poles with non-negative real parts.

The system is also controllable and has no multivariable zeros. 


\section{CONTROL STRATEGIES}

This chapter presents the control strategies applied to the unicycle.

\subsection{Linear Quadratic Regulator}

\subsubsection{Linear Quadratic Regulator}

The linear quadratic regulator (LQR) is an optimal controller which aims at minimizing a particular cost function (OGATA, 2011).

Considered a system, as equation (3.32), the cost function is described as

$$
J=\int_{0}^{\infty} x(t)^{\top} Q x(t)+u(t)^{\top} R u(t) d x
$$

where, $Q$ and $R$ are, respectively, semi-definite and definite positive weighting matrices. The solution of this problem is a state feedback as

$$
u(t)=K x(t) .
$$

where, $K$ is the matrix controller calculated by

$$
K=R^{-1} B^{\top} P
$$

where, $P$ is the solution of the continuous algebraic Riccati equation (CARE)

$$
A^{\top} P+P A-P B R^{-1} B^{\top} P+Q=0
$$

\subsubsection{Bryson's rule}

A first choice for matrices $Q$ and $R$ can be given by Bryson's rule (FRANKLIN; POWELL; WORKMAN, 2006). This technique is a form of normalization of the state variables, so, it is strongly recommended to systems with state variables with different 
units. It assumes diagonal $\mathrm{Q}$ and $\mathrm{R}$ matrices, such that

$$
Q_{i i}=\frac{1}{\text { maximum variation accepted of } x_{i}^{2}}
$$

and,

$$
R_{j j}=\frac{1}{\text { maximum variation accepted of } u_{j}^{2}},
$$

where, $Q_{i i}$ and $R_{j j}$ being, respectively, the diagonal element of the $i_{t h}$ and the $j_{t h}$ row of $Q$ and $R$.

Although Bryson's rules is a practical form to determine matrices $Q$ and $R$, oftentimes it is not enough, but can be a starting point to a trial-and-error procedure.

\subsubsection{Control of the simplified model}

Aiming to equilibrate the unicycle, the linear model can be simplified removing the positions of the reaction wheel and the travel wheel $\left(\theta_{d}\right.$ and $\theta_{w}$, respectively).

By Brison's rule, considering that the maximum angles of the system are approximately $15^{\circ}$ and the maximum velocity of the motors are $118[\mathrm{rpm}]$, after a few attempts, the results LQR matrices are

$$
Q=\left[\begin{array}{cccccc}
0.0065 & 0 & 0 & 0 & 0 & 0 \\
0 & 14.5903 & 0 & 0 & 0 & 0 \\
0 & 0 & 10 & 0 & 0 & 0 \\
0 & 0 & 0 & 0.0065 & 0 & 0 \\
0 & 0 & 0 & 0 & 14.5903 & 0 \\
0 & 0 & 0 & 0 & 0 & 1
\end{array}\right]
$$

and

$$
R=\left[\begin{array}{ll}
1 & 0 \\
0 & 1
\end{array}\right]
$$

With these matrices, the LQR controller is

$$
K_{L Q R}=\left[\begin{array}{cccccc}
0.2173 & 16.2566 & 4.7481 & 0 & 0 & 0 \\
0 & 0 & 0 & 0.3807 & 11.2857 & 2.1597
\end{array}\right] .
$$

Although the controller worked fine in simulation, it was not possible to stabilize the reaction wheel system. This may be caused by some uncertainties parameters, like the 
viscous friction coefficient and mechanical parameters, such as moment of inertia and position of the center if mass.

But, as the system is apparently very close to stability, after some attempts and observing the operation of the plant, the matrices

$$
Q=\left[\begin{array}{cccccc}
0.0065 & 0 & 0 & 0 & 0 & 0 \\
0 & 14.5903 & 0 & 0 & 0 & 0 \\
0 & 0 & 20 & 0 & 0 & 0 \\
0 & 0 & 0 & 0.0065 & 0 & 0 \\
0 & 0 & 0 & 0 & 14.5903 & 0 \\
0 & 0 & 0 & 0 & 0 & 1
\end{array}\right]
$$

and

$$
R=\left[\begin{array}{ll}
1 & 0 \\
0 & 1
\end{array}\right]
$$

are found, resulting in the following LQR gain matrix:

$$
K_{L Q R}=\left[\begin{array}{cccccc}
0.2173 & 18.0798 & 5.9749 & 0 & 0 & 0 \\
0 & 0 & 0 & 0.3561 & 10.7524 & 2.1300
\end{array}\right] \text {. }
$$

As will be shown in Chapter 5, this controller stabilizes the system. It is worth mentioning that the matrix is block diagonal, which was already expected, because matrices (3.37) and (3.38) are decoupled.

\subsection{Linear matrix inequality}

Considering a linear system of the form

$$
\dot{x}=A x,
$$

which is asymptotically stable if and only if there exists a symmetric matrix $P$ such that the function

$$
V(x)=x^{\prime} P x
$$

satisfy the Lyapunov theorem (GEROMEL, 2011), that is

$$
\begin{array}{r}
P>0 ; \\
A^{\prime} P+P A<0 .
\end{array}
$$




\subsubsection{Norm $\mathcal{H}_{2}$}

The constraints (4.15) and (4.16) form a linear matrix inequality (LMI), so is possible to calculate the controller via LMI to stabilize the system. Besides that, a performance index can be considered, for instance, by minimizing the norm $\mathcal{H}_{2}$.

The $\mathcal{H}_{2}$ norm of a system with the impulse response $h(t)=C_{z} e^{A t} B_{w}$ can be calculated as

$$
\|H(s)\|_{2}^{2}=\int_{0}^{\infty} \operatorname{Tr}\left(h(t) h(t)^{\prime}\right) d t=\int_{0}^{\infty} \operatorname{Tr}\left(C_{z} e^{A t} B_{w} B_{w}^{\prime} e^{A^{\prime} t} C_{z}^{\prime}\right) d t
$$

than

$$
\|H(s)\|_{2}^{2}=C_{z} \int_{0}^{\infty} \operatorname{Tr}\left(e^{A t} B_{w} B_{w}^{\prime} e^{A^{\prime} t}\right) d t C_{z}^{\prime}=\operatorname{Tr}\left(C_{z} W_{c} C_{z}^{\prime}\right)
$$

where $W_{c}$ is the controllability grammar.

Considering the linear system

$$
\begin{aligned}
\dot{x} & =A x+B u+B_{w} w \\
z & =C_{z} x+D_{z} u
\end{aligned}
$$

its closed loop form is

$$
\begin{aligned}
\dot{x} & =A_{c l} x+B_{w} w \\
z & =C_{c l} x,
\end{aligned}
$$

where $A_{c l}=(A+B K)$ and $C_{c l}=\left(C_{z}+D_{z} K\right)$. The optimal $\mathcal{H}_{2}$ controller is calculated by

$$
\min _{P=P^{\prime}>0} \operatorname{Tr}\left(C_{c l} P C_{c l}^{\prime}\right)
$$

subject to

$$
A_{c l} P+P A_{c l}^{\prime}+B_{w} B_{w}^{\prime}<0 .
$$

This problem is the same that

$$
\min _{X=X^{\prime}>0} \operatorname{Tr}(X)
$$

subject to

$$
\begin{array}{r}
C_{c l} P C_{c l}^{\prime}-X<0, \\
A_{c l} P+P A_{c l}^{\prime}+B_{w} B_{w}^{\prime}<0 .
\end{array}
$$

To the next steps, consider the Finsler' Lemma (OLIVEIRA; SKELTON, 2001). 
Finsler' Lemma 1. Considering $v \in \mathbb{R}, \mathcal{Q} \in \mathbb{R}^{n \times n}$ and $\mathcal{B} \in \mathbb{R}^{m \times n}$, with $\operatorname{rank}(\mathcal{B})<n$ and $\mathcal{B}^{\perp}$ a base of the null space of $\mathcal{B}$. So, the following conditions are equivalent:

- $v^{\prime} \mathcal{Q} v<0, \forall v \neq 0: \mathcal{B} v=0$

- $\mathcal{B}^{\perp^{\prime}} \mathcal{Q} \mathcal{B}^{\perp}<0$

- $\exists \mu \in \mathbb{R}: \mathcal{Q}-\mu \mathcal{B}^{\prime} \mathcal{B}<0$

- $\exists \mathcal{X} \in \mathbb{R}^{n \times m}: \mathcal{Q}+\mathcal{X} \mathcal{B}+\mathcal{B}^{\prime} \mathcal{X}^{\prime}<0$

In other words, if a condition of the Fisler' lemma is satisfied, the other three are also true. The inequality $(4.24)$ can be rewritten as

$$
\underbrace{\left[\begin{array}{ll}
I & C_{c l}
\end{array}\right]}_{\mathcal{B}^{\perp^{\prime}}} \underbrace{\left[\begin{array}{cc}
-X & 0 \\
0 & P
\end{array}\right]}_{\mathcal{Q}} \underbrace{\left[\begin{array}{c}
I \\
C_{c l}^{\prime}
\end{array}\right]}_{\mathcal{B}^{\perp}}<0
$$

as can be seen, it is equivalent to the second condition of Finsler' lemma, so, using the fourth condition, it results in

$$
\underbrace{\left[\begin{array}{cc}
-X & 0 \\
0 & P
\end{array}\right]}_{\mathcal{Q}}+\underbrace{\left[\begin{array}{c}
-F \\
-G
\end{array}\right]}_{\mathcal{X}} \underbrace{\left[\begin{array}{ll}
-C_{c l}^{\prime} & I
\end{array}\right]}_{\mathcal{B}}+\underbrace{\left[\begin{array}{c}
-C_{c l} \\
I
\end{array}\right]}_{\mathcal{B}^{\prime}} \underbrace{\left[\begin{array}{ll}
-F^{\prime} & -G^{\prime}
\end{array}\right]}_{\mathcal{X}^{\prime}}<0,
$$

which is equal to

$$
\left[\begin{array}{cc}
-X+F C_{c l}^{\prime}+C_{c l} F^{\prime} & -F+C_{c l} G^{\prime} \\
-F^{\prime}+G C_{c l}^{\prime} & P-G-G^{\prime}
\end{array}\right]<0 .
$$

The inequality (4.25) can be written so as to satisfy the second condition of the Finsler' lemma, as

$$
\underbrace{\left[\begin{array}{lll}
I & A_{c l} & B_{w}
\end{array}\right]}_{\mathcal{B}^{\perp^{\prime}}} \underbrace{\left[\begin{array}{ccc}
0 & P & 0 \\
P & 0 & 0 \\
0 & 0 & I
\end{array}\right]}_{\mathcal{Q}} \underbrace{\left[\begin{array}{c}
I \\
A_{c l}^{\prime} \\
B_{w}^{\prime}
\end{array}\right]}_{\mathcal{B}^{\perp}}<0
$$

Considering the forth condition, it is equivalent to

$$
\underbrace{\left[\begin{array}{lll}
0 & P & 0 \\
P & 0 & 0 \\
0 & 0 & I
\end{array}\right]}_{\mathcal{Q}}+\underbrace{\left[\begin{array}{cc}
X_{1} & X_{4} \\
X_{2} & X_{5} \\
X_{3} & X_{6}
\end{array}\right]}_{\mathcal{X}} \underbrace{\left[\begin{array}{ccc}
A_{c l}^{\prime} & -I & 0 \\
B_{c l}^{\prime} & 0 & -I
\end{array}\right]}_{\mathcal{B}}+\underbrace{\left[\begin{array}{cc}
A_{c l} & B_{w} \\
-I & 0 \\
0 & -I
\end{array}\right]}_{\mathcal{B}^{\prime}} \underbrace{\left[\begin{array}{ccc}
X_{1}^{\prime} & X_{2}^{\prime} & X_{3}^{\prime} \\
X_{4}^{\prime} & X_{5}^{\prime} & X_{6}^{\prime}
\end{array}\right]}_{\mathcal{X}^{\prime}}<0 .
$$


Hence, making $X_{1}=G^{\prime}, X_{2}=\xi G^{\prime}, X_{6}=H^{\prime}, X_{3}=X_{4}=X_{5}=0, Z=K G$ and replacing $A_{c l}$ and $C_{c l}$, the problem of stabilizing the system and minimizing the $\mathcal{H}_{2}$ norm can be written as

$$
\min _{X=X^{\prime}>0} \operatorname{Tr}(X)
$$

subject to

$$
\begin{gathered}
{\left[\begin{array}{cc}
-X & C_{z} G+D_{z} Z \\
\star & P-G-G^{\prime}
\end{array}\right]<0,} \\
{\left[\begin{array}{ccc}
A G+B Z+G^{\prime} A^{\prime}+Z^{\prime} B^{\prime} & P-G^{\prime}+\xi(A G+B Z) & B_{w} H \\
\star & -\xi\left(G+G^{\prime}\right) & 0 \\
\star & \star & I-H-H^{\prime}
\end{array}\right]<0 .}
\end{gathered}
$$

\subsubsection{Parametric uncertainties}

The idea of considering the optimal $\mathcal{H}_{2}$ control comes from the fact that the optimal LQR control is a particular case of the $\mathcal{H}_{2}$. Making $Q=C_{z}^{\prime} C_{z}, R=D_{z}^{\prime} D_{z}$ and $N=C_{z}^{\prime} D_{z}$, the problem of minimizing the $\mathcal{H}_{2}$ norm becomes the LQR problem. But, with the LMI methodology is possible to take into account parametric uncertainties (OLIVEIRA; PERES, 2008).

After analyzing the $3 \mathrm{~d}$ CAD model, it was observed that the main mechanical uncertainties could come from the moment of inertia and from the distances regarding the center of mass that affect the reaction wheel system. It was also considered that viscous friction of the reaction wheel was not precisely estimated. The following parameters range values are considered:

- $0.0692 \leq J_{b w} \leq 0.0846$;

- $0.0108 \leq J_{r} \leq 0.0162$;

- $0.1747 \leq L \leq 0.2145$

- $0.1231 \leq d \leq 0.1619$

- $0.0900 \leq B_{v r} \leq 0.1100$

Thus, the uncertain linear system can be written as

$$
\dot{x}=A(\alpha) x+B(\alpha) u
$$


where

$$
\begin{aligned}
& A(\alpha)=\sum_{k=1}^{32} \alpha_{k} A_{k} \\
& B(\alpha)=\sum_{k=1}^{32} \alpha_{k} B_{k} .
\end{aligned}
$$

The closed loop is

$$
A_{c l}(\alpha)=A(\alpha)+B(\alpha) K
$$

Considering the extremes of each value, the set results in a convex polytope with 32 vertices, and the convex combination of them results in a internal point. The $\operatorname{set}^{1}$ of $\alpha$ is defined as

$$
\Xi=\left\{\alpha \in \mathbb{R}^{N} \mid \alpha_{i}>0, \quad \sum_{k=1}^{N} \alpha_{k}=1\right\},
$$

where $N$ is the number of vertices, in this case 32 . The system

$$
\dot{x}=A_{c l}(\alpha) x, \quad A_{c l}(\alpha)=\sum_{k=1}^{N} \alpha_{k} A_{c l k},
$$

is stable for all $\alpha \in \Xi$ if there exists a matrix $P(\alpha)=P(\alpha)^{\prime}>0$ such that

$$
\min _{X=X^{\prime}>0} \operatorname{Tr}(X)
$$

subject to

$$
\begin{aligned}
& {\left[\begin{array}{cc}
-X & C_{z} G+D_{z} Z \\
\star & P(\alpha)-G-G^{\prime}
\end{array}\right]<0} \\
& {\left[\begin{array}{rr}
A(\alpha) G+B(\alpha) Z+G^{\prime} A(\alpha)^{\prime}+Z^{\prime} B(\alpha)^{\prime} & \ldots \\
\star & \cdots \\
\star & \cdots
\end{array}\right.} \\
& \left.\begin{array}{ccc}
\ldots & P(\alpha)-G^{\prime}+\xi(A(\alpha) G+B(\alpha) Z) & B_{w} H(\alpha) \\
\ldots & -\xi\left(G+G^{\prime}\right) & 0 \\
\ldots & \star & I-H(\alpha)-H(\alpha)^{\prime}
\end{array}\right]<0,
\end{aligned}
$$

and $P(\alpha)$ is considered a first degree polynomial.

The ROLMIP (AGULHARI; OLIVEIRA; PERES, 2012) is a software to solve LMIs that was used in this project. It is designed to work specifically with optimization problems presenting parameter-dependent variables with parameters in the unit simplex.

\footnotetext{
${ }^{1}$ This set is the unit simplex.
} 
In order to compare with the LQR control and to verify the influence of the uncertain parameters, the following matrices are considered ${ }^{2}$

$$
C_{z}=\left[\begin{array}{cccccc}
0.080926 & 0 & 0 & 0 & 0 & 0 \\
0 & 3.8197 & 0 & 0 & 0 & 0 \\
0 & 0 & 3.1623 & 0 & 0 & 0 \\
0 & 0 & 0 & 0.080926 & 0 & 0 \\
0 & 0 & 0 & 0 & 3.1623 & 0 \\
0 & 0 & 0 & 0 & 0 & 1 \\
0 & 0 & 0 & 0 & 0 & 0 \\
0 & 0 & 0 & 0 & 0 & 0
\end{array}\right]
$$

and

$$
D_{z}^{\prime}=\left[\begin{array}{llllllll}
0 & 0 & 0 & 0 & 0 & 0 & 1 & 0 \\
0 & 0 & 0 & 0 & 0 & 0 & 0 & 2
\end{array}\right]
$$

in this way, $C_{z}^{\prime} C_{z}=Q, D_{z}^{\prime} D_{z}=\left[\begin{array}{ll}1 & 0 \\ 0 & 4\end{array}\right]$ and $C_{z}^{\prime} D_{z}=0$, which are the initial proposed Bryson's rule matrices. The second diagonal element of matrix $D_{z}^{\prime} D_{z}$ is set four times the first one in order to decrease the gain of the travel wheel. These matrices choices result in the following controller:

$$
K_{L M I}=\left[\begin{array}{cccccc}
0.2215 & 20.5307 & 5.9067 & 0 & 0 & 0 \\
0 & 0 & 0 & 0.3808 & 11.2893 & 2.1612
\end{array}\right],
$$

with the $\mathcal{H}_{2}$ norm equal to 303.6285.

The block diagonal structure of the controller was imposed, since the linear model is decoupled.

\footnotetext{
${ }^{2}$ The matrix $B_{w}$ is considered a column vector of 1 with dimension equal to the number of states .
} 


\section{SIMULATION AND PRACTICAL RESULTS}

This chapter presents the simulation and practical results of each controller.

\subsection{Simulation of the LQR controller}

All the simulations in this project were made in MatLab/Simulink using the non-linear model (3.26). The Simulink diagram can be seen in Appendix B. As the implementation in the real system was embedded in a microcontroller, the simulation was performed in discrete time (considering the $\mathrm{AD}$ and $\mathrm{DA}$ converter, $\mathrm{ZOH}$ ) with a sampling rate equal to of $200[\mathrm{~Hz}]$. The derivatives were approximated using the backward Euler's method, i.e,

$$
\dot{\theta}=\frac{\theta[k]-\theta[k-1]}{T s} .
$$

Figure 24 shows the simulation (4.9) without considering measurement noise or deadzone of the actuators. Initial condition of $-5^{\circ}$ for $\varphi$ and $5^{\circ}$ for $\psi$ are considered.

As verified, the controller can stabilize the plant without saturating the actuators, and variables $\theta_{r}$ and $\theta_{w}$ stabilize at non-zero points, which was expected because these states were removed for the controller project.

Figure 25 shows the torque applied to each motor. As observed, the torque remained smaller than the stall torque.

Although the controller works very well, the simulation did not consider some real effects of the plant. Hence, measurement noise and the dead zone of the motors were included in the nonlinear model. The dead zones were obtained by varying the voltage of the motors $(P W M)$ until the motor starts to move. After some tests, the dead zone of the reaction wheel and the travel wheel are approximately $9 \%$ of $P W M$ and $12 \%$ of $P W M$, respectively

After some tests with the IMU, the noise was assumed to be a white noise with 
Figure 24: Simulation of the LOR controller.
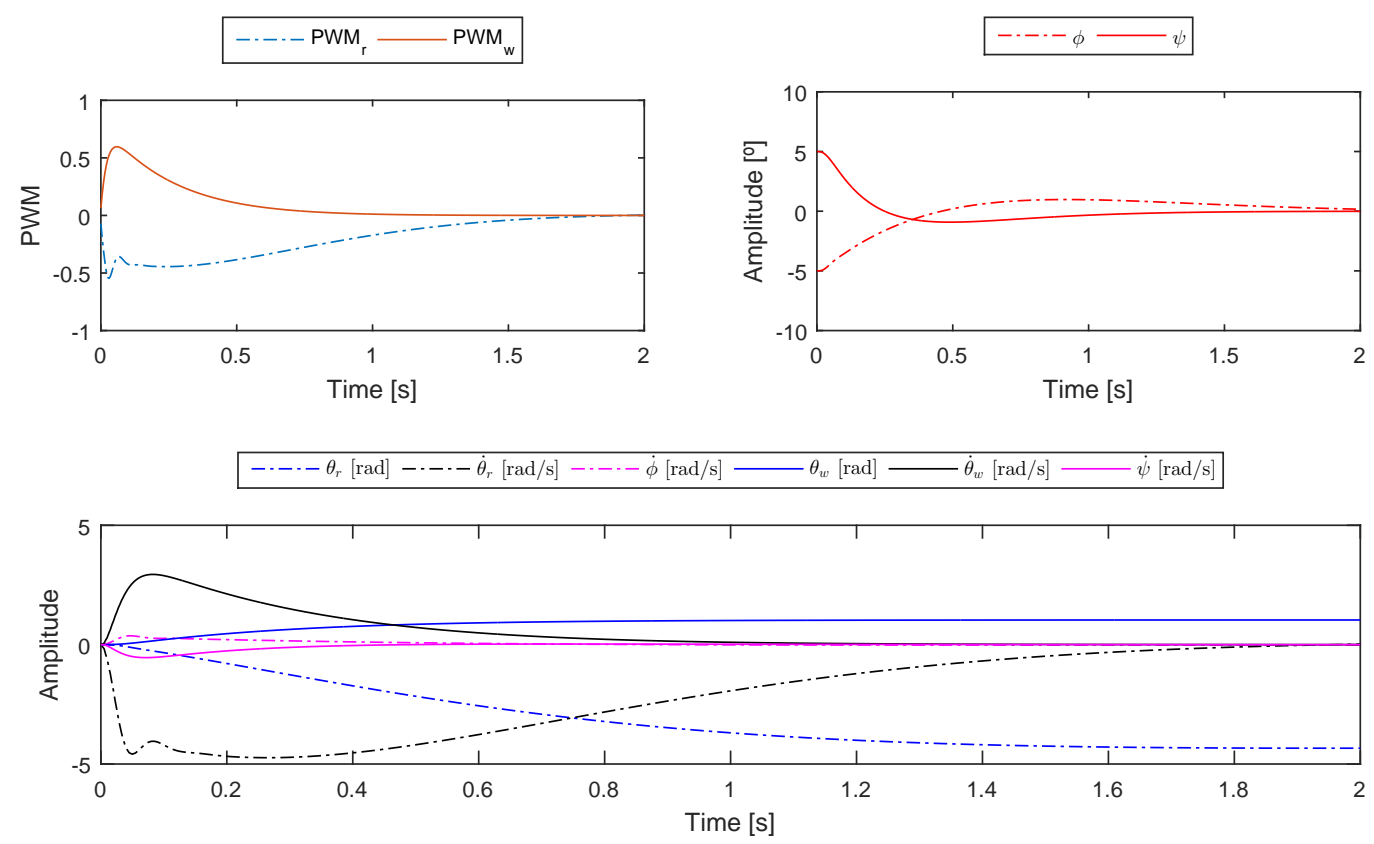

Source: Author.

Fịure 25: Control effort which LQR controller.

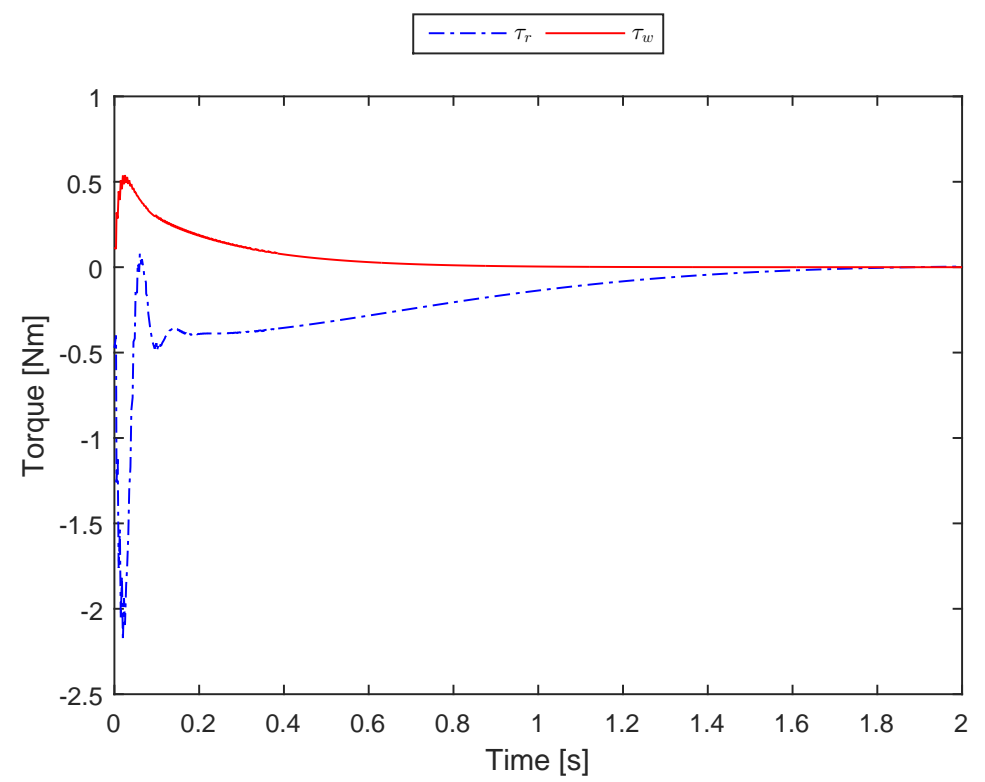

Source: Author. 
variance of $10^{-4}[\mathrm{rad}]$ and $10^{-4}[\mathrm{rad} / \mathrm{s}]$ for the angular position and the angular velocity.

For the encoders, a sinusoidal signal is applied to the motors. The normalized variance of the difference between the sine and the output is approximately the variance of the encoder noise, which is too small. Thus, it was considered a white noise with a variance of $10^{-7}[\mathrm{rad}]$.

Figure 26 shows the simulation results of the controller considering noise and dead zone, while Figure 27 shows the torques of the actuators. As verified, even with the noise and the dead zone, the controller stabilizes the plant.

Figure 26: Simulation of the LQR considering noise and dead zone.
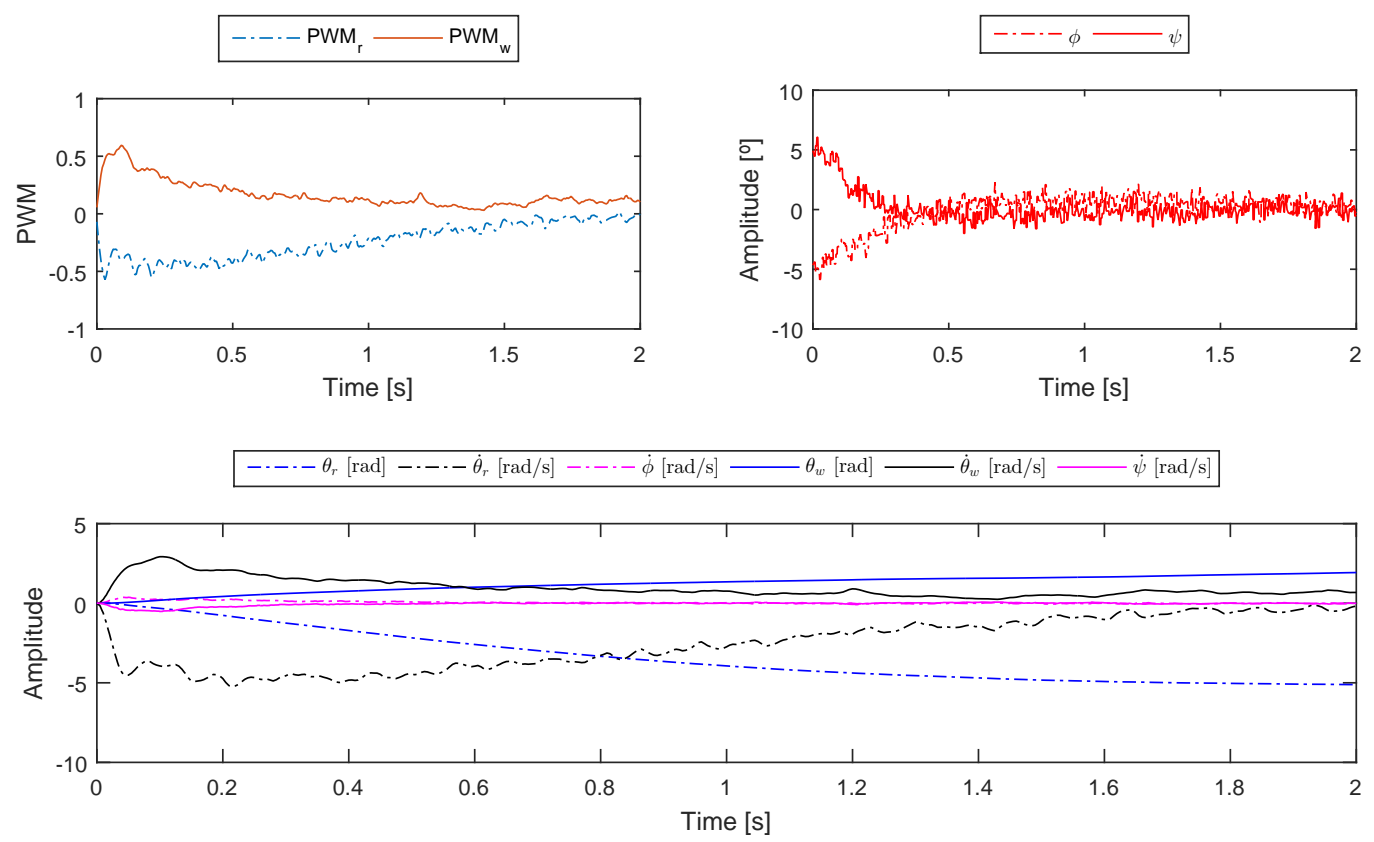

Source: Author. 
Figure 27: Control effort with LQR considering noise and dead zone.

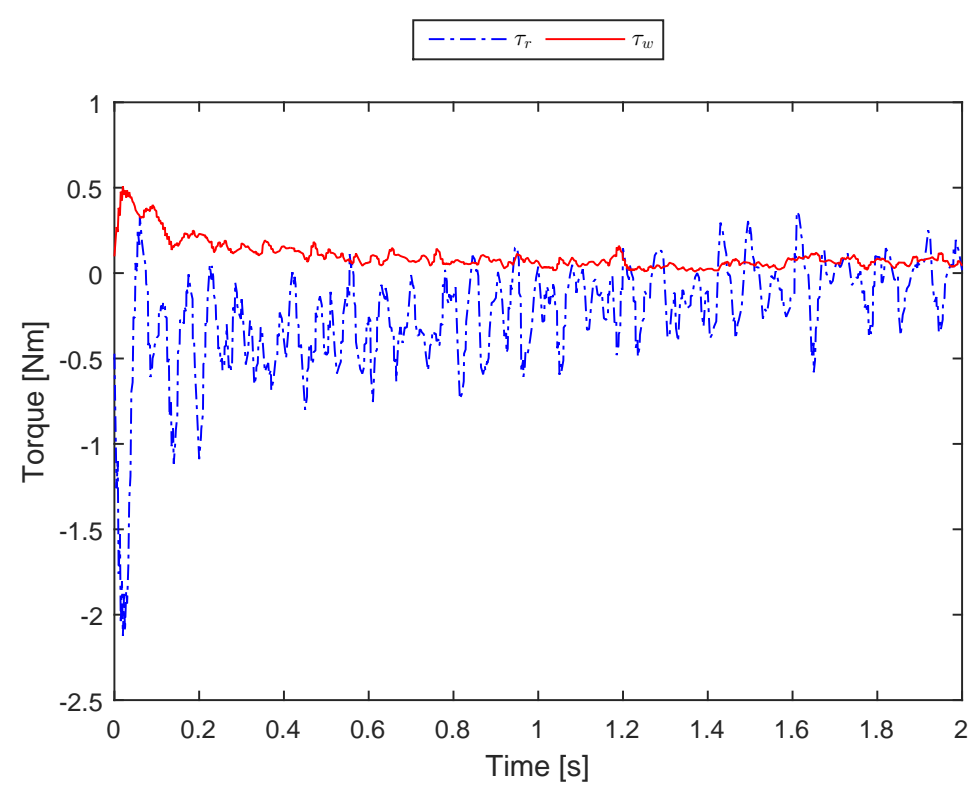

Source: Author.

\subsection{Simulation of the $\mathcal{H}_{2}$ controller}

Considering the plant without the measurement noise and dead zone, Figure 28 shows the simulation of the controller (4.45) with the same initial condition of the Figure 24. The control effort is shown in Figure 29. As expected, the $\mathcal{H}_{2}$ controller via LMI shows good results in simulation.

Considering now dead zone and measurement noise, the simulation results are shown in Figure 30, and the control effort is presented in Figure 31.

Both controllers were able to stabilize the simulated system, even with measurement noise and actuator dead zone. 
Figure 28: Simulation of the $\mathcal{H}_{2}$ controller.
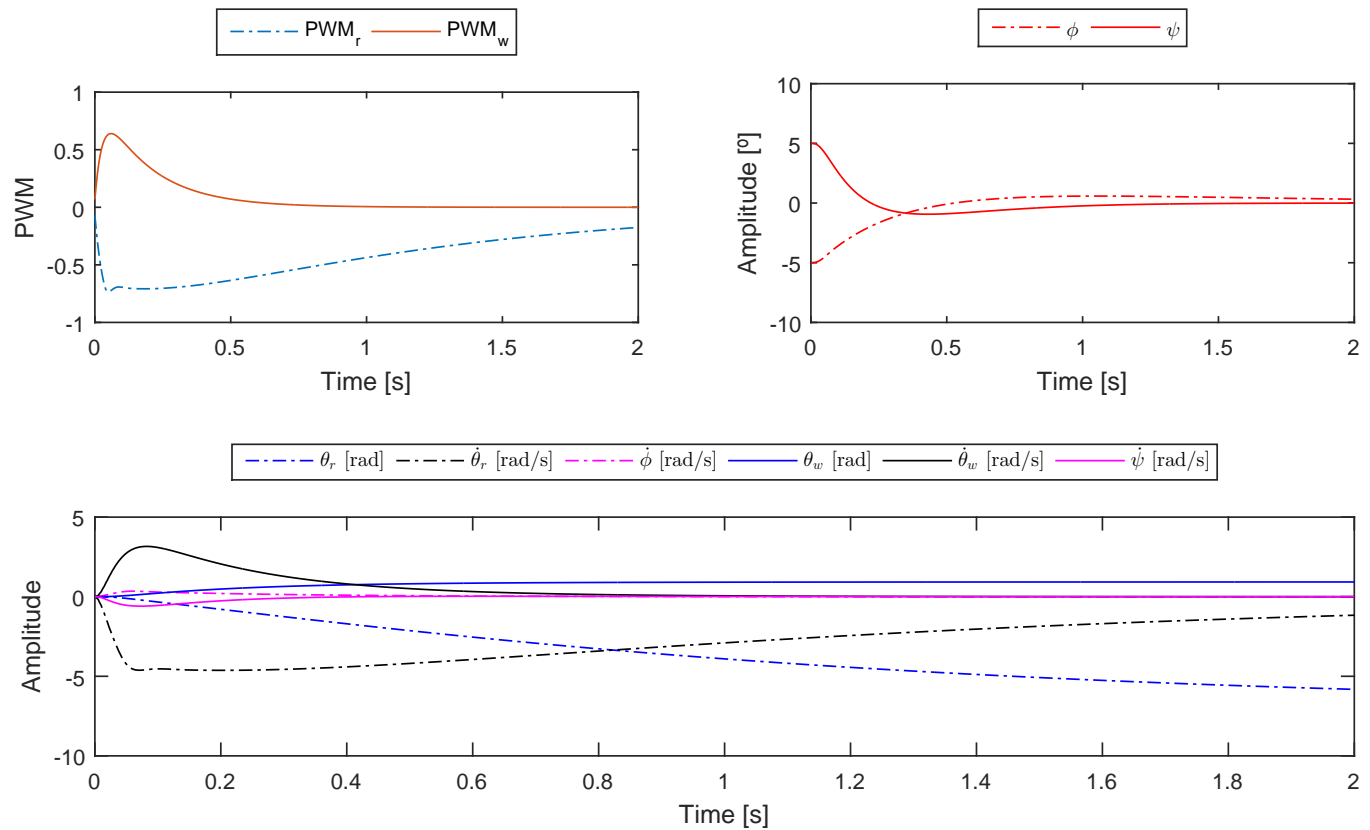

Source: Author.

Figure 29: Control effort with $\mathcal{H}_{2}$ controller.

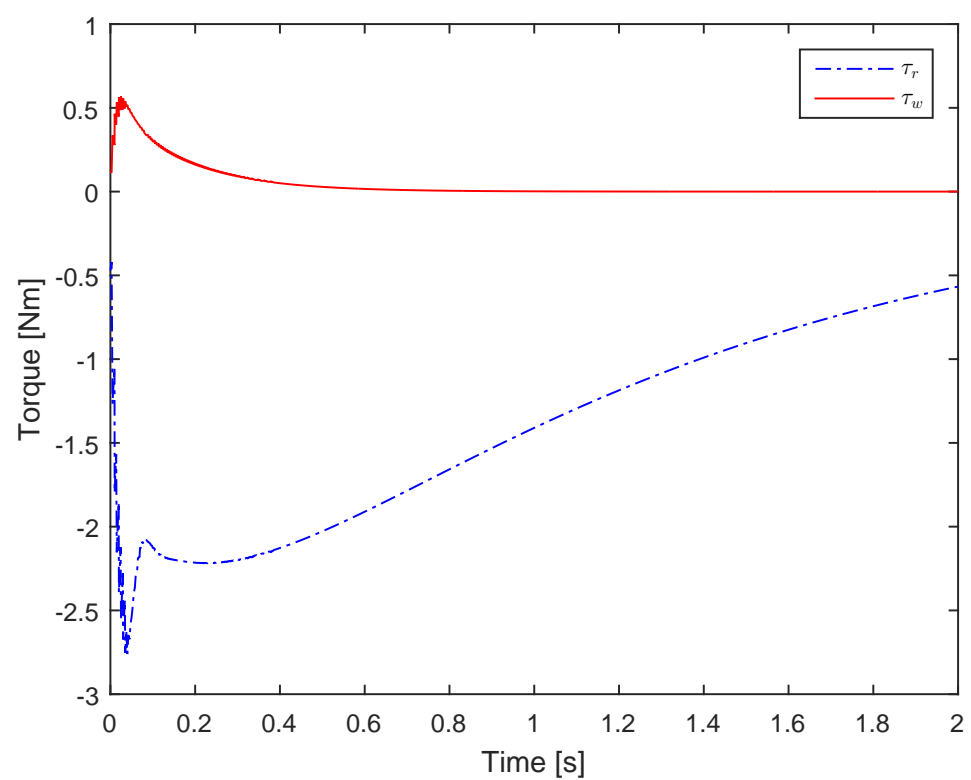

Source: Author. 
Figure 30: Simulation with $\mathcal{H}_{2}$ controller considering noise and dead zone.
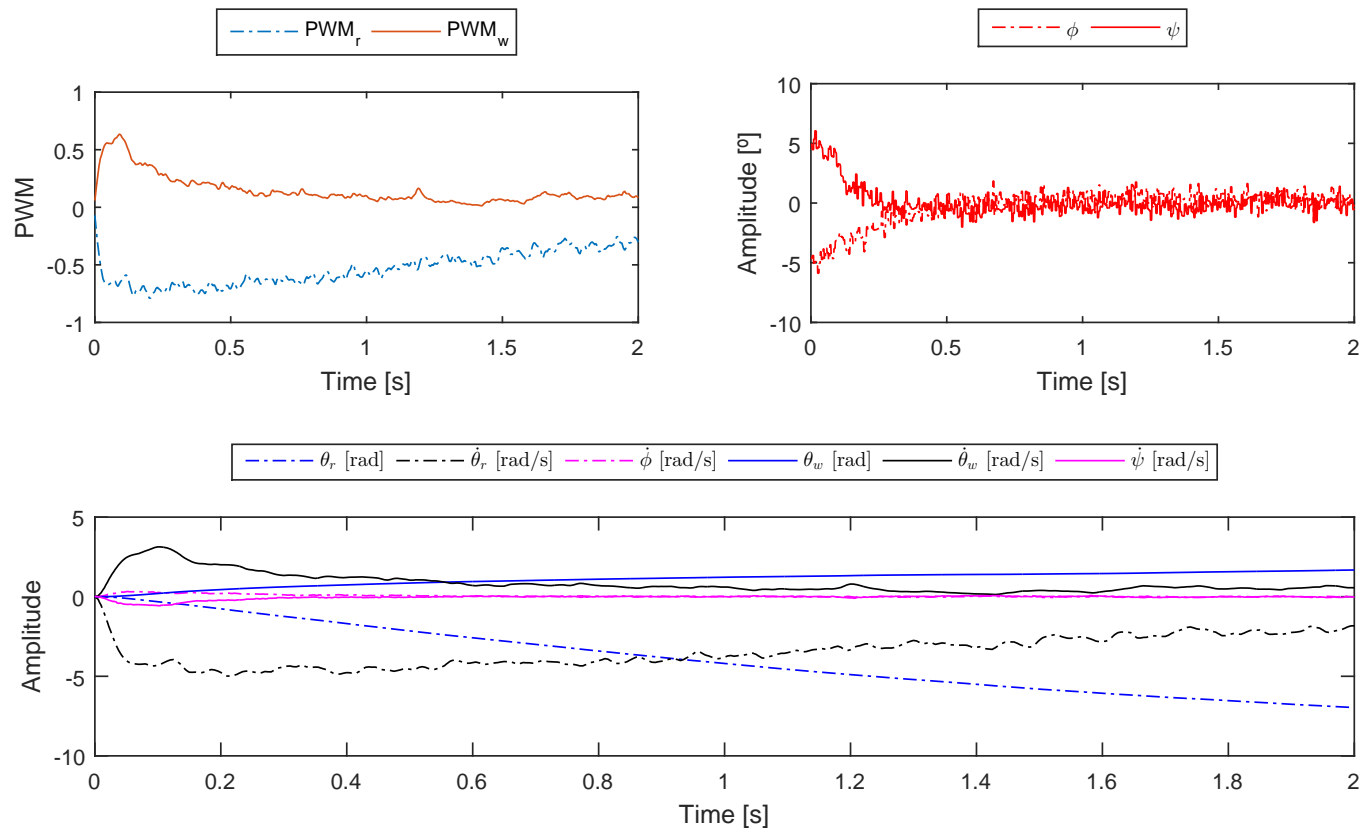

Source: Author.

Figure 31: Control effort of the $\mathcal{H}_{2}$ considering noise and dead zone.

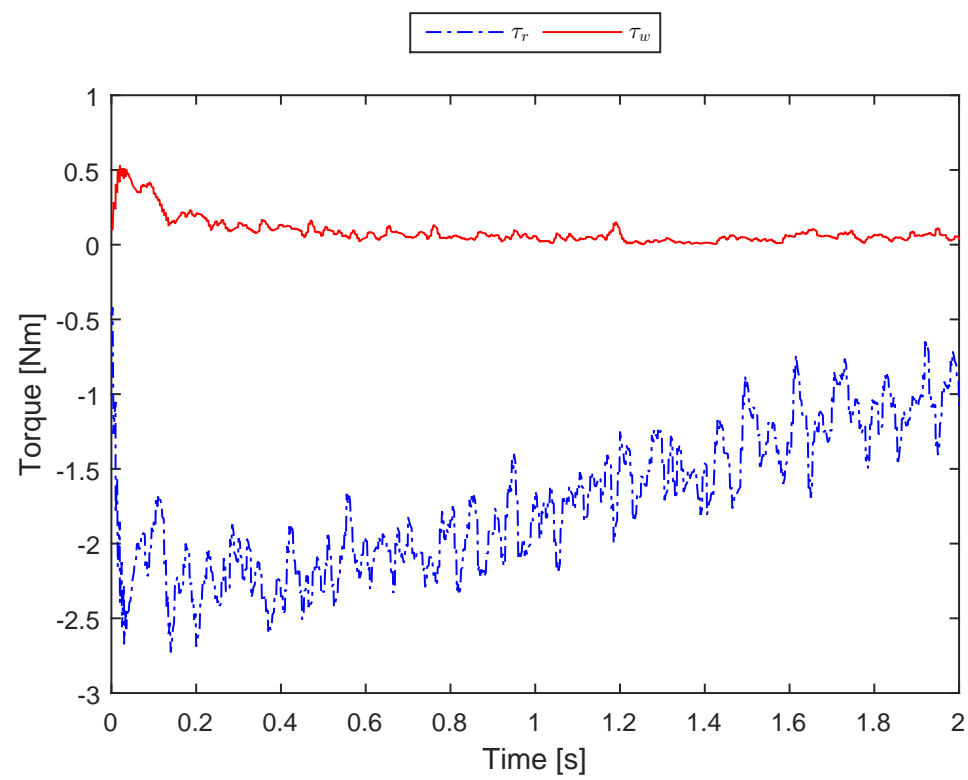

Source: Author. 


\subsection{Practical results of the LQR}

With the simulation working, the next step consists in the practical implementation. The unicycle had a microcontroller (FRDM-K64F) and the control algorithm is embedded on it.

The angular positions and velocities are measured by the IMU sensor and the angular positions of the each motor by encoders. The travel wheel angular velocities are estimated according to equation (5.1).

Figure 32 shows the unicycle performance with the LQR controller. As can be seen, the controller was able to stabilize the system, but the pitch angle presented a small oscillation, mainly due to backlash of the gearbox and wheel mounting.

Figure 32: Practical stabilization test with LQR.
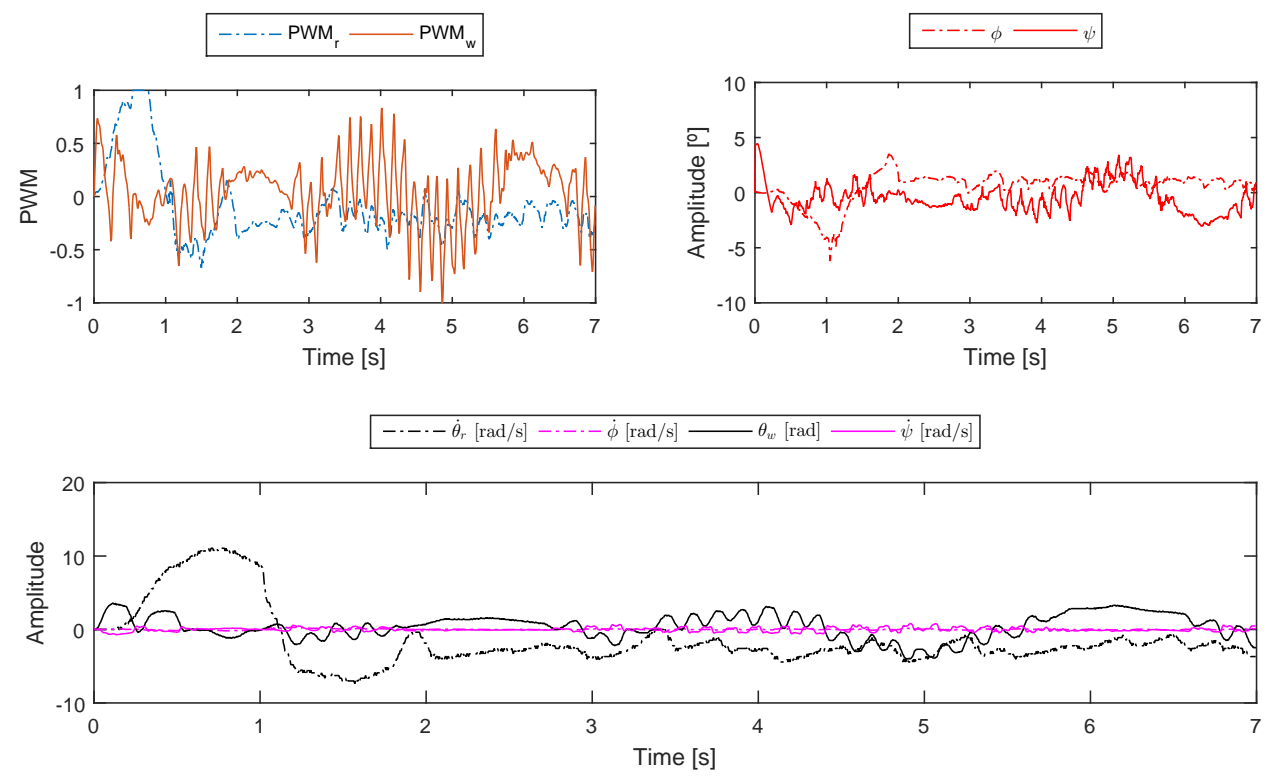

Source: Author.

To test the disturbance rejection, a small disturbance was applied only in roll angle, and the result is shown in Figure 33. The dashed line indicates the disturbance instant. The system remained stable, but the control signal has reached values very close to saturation.

The disturbance response in the pitch angle is presented in Figure 34. Once again, the disturbance was rejected, ensuring stability, but the control signal has reached values very close to saturation.

Lastly, a diagonal disturbance is applied, and the results are shown in Figure 35. As 
Figure 33: Practical roll angle disturbance test with LQR.
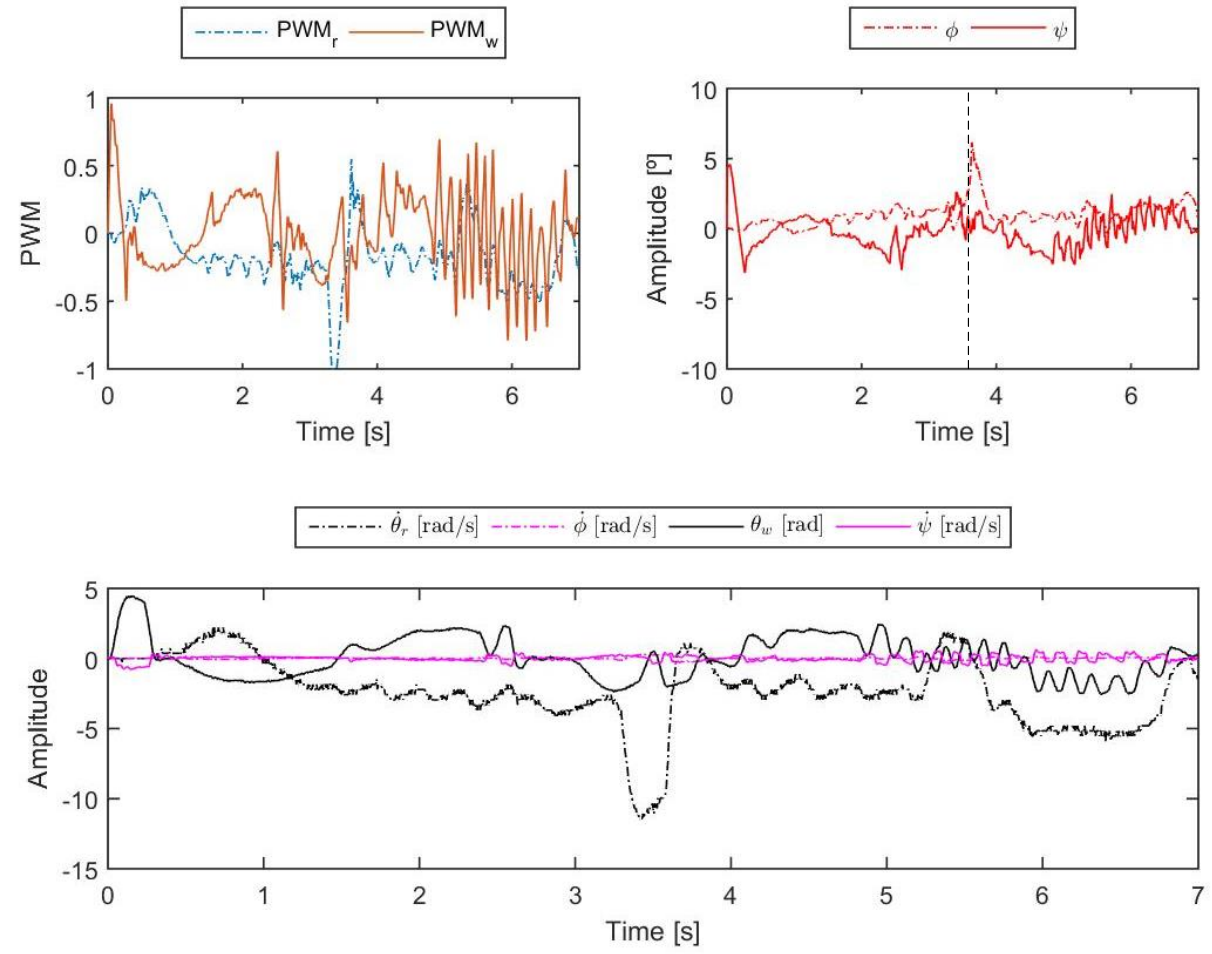

Source: Author.

Figure 34: Practical pitch angle disturbance test with LQR.
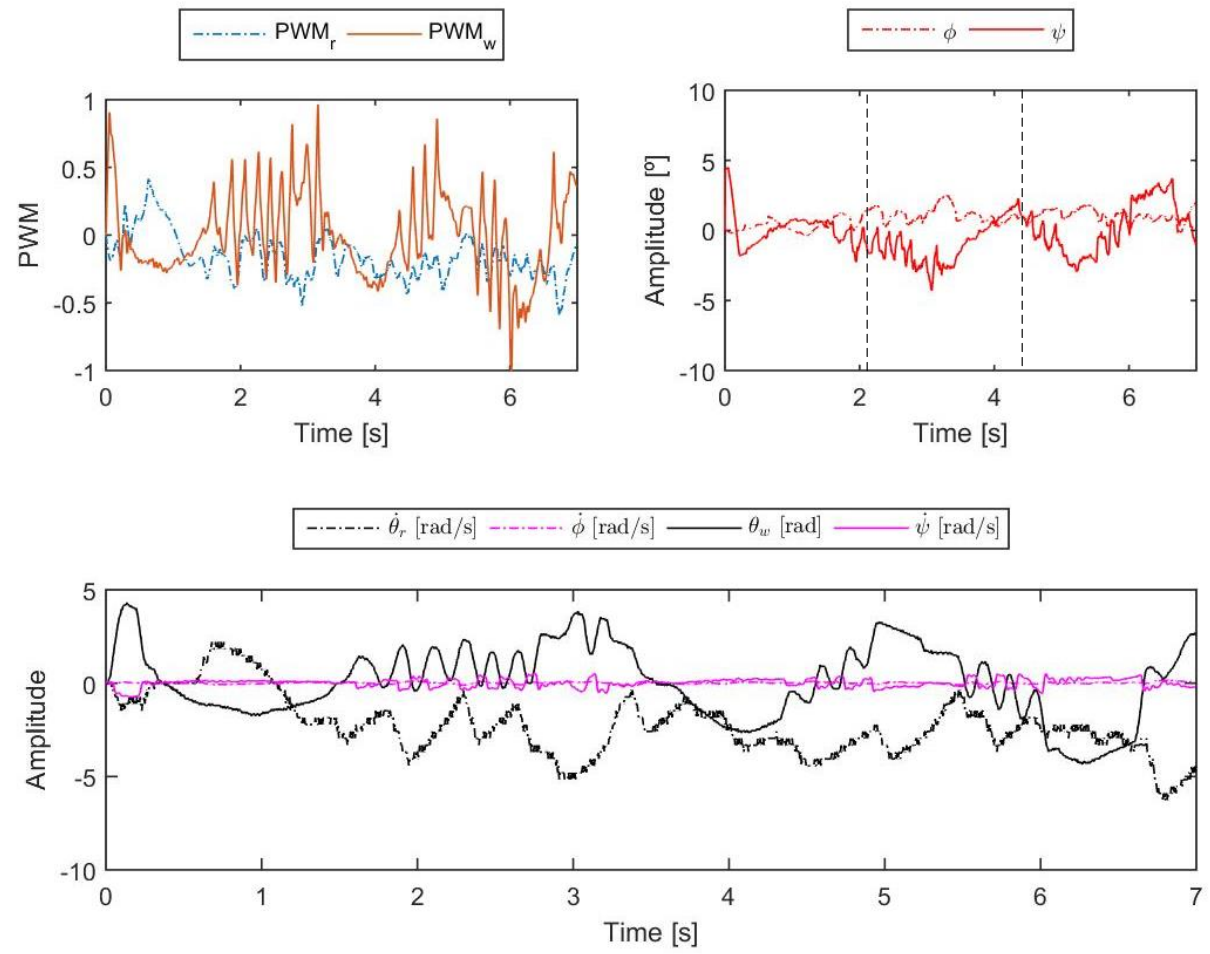

Source: Author. 
Figure 35: Practical pitch and roll angle disturbance test with LQR.
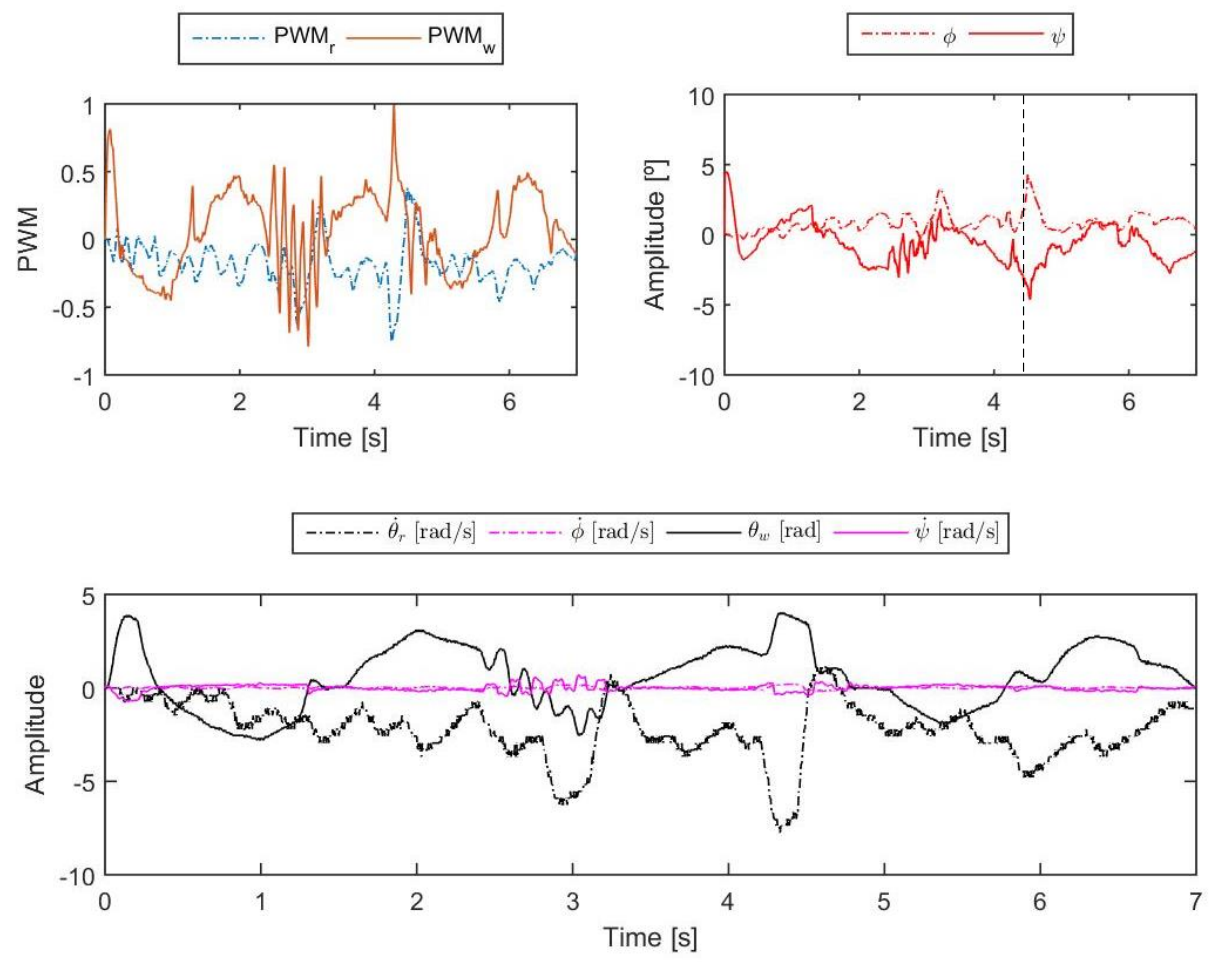

Source: Author.

expected, the two angles were stabilized and the coupling was practically null.

\subsection{Practical results of the $\mathcal{H}_{2}$ controller}

Both LQR and $\mathcal{H}_{2}$ control are state feedback, so, their control algorithm are the same. The performance with $\mathcal{H}_{2}$ controller synthesized via LMI can be seen in Figure 36 . The unicycle was released in instant 1 second, so, the peak of roll angle in this instant is the initial condition. As can be seen, the controller performed well, but the pitch angle presented a small oscillation too.

Figure 37 shows the practical results when applied a disturbance in the roll angle. The instant of the disturbance is marked by a dashed line.

The results concerning the disturbance rejection in the pitch angle are shown in Figure 38.

Lastly, Figure 39 shows the results of the diagonal disturbance rejection.

All the results obtained with the $\mathcal{H}_{2}$ control via LMI were very similar to LQR results, because, the controllers (4.45) and (4.12) are practically the same. The advantage of using 
Figure 36: Practical stabilization test with $\mathcal{H}_{2}$ controller.
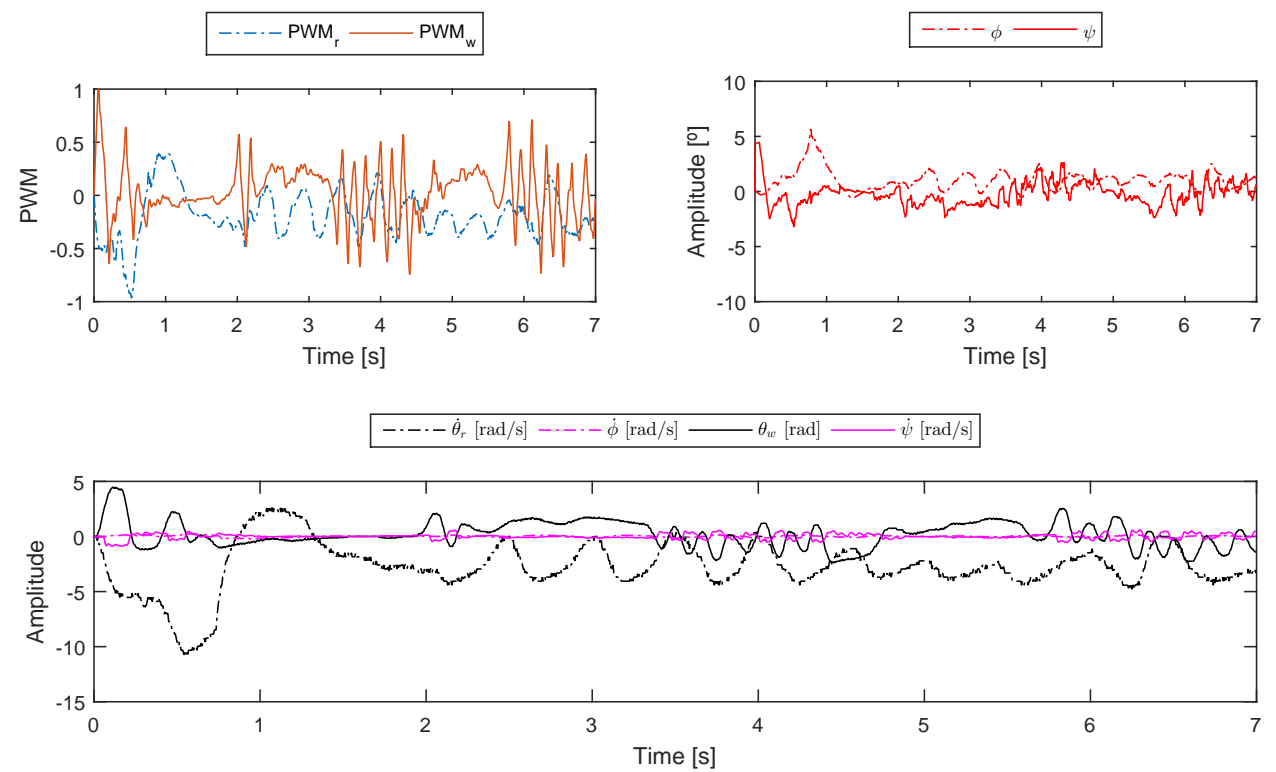

Source: Author.

Figure 37: Practical roll angle disturbance test with $\mathcal{H}_{2}$ controller.
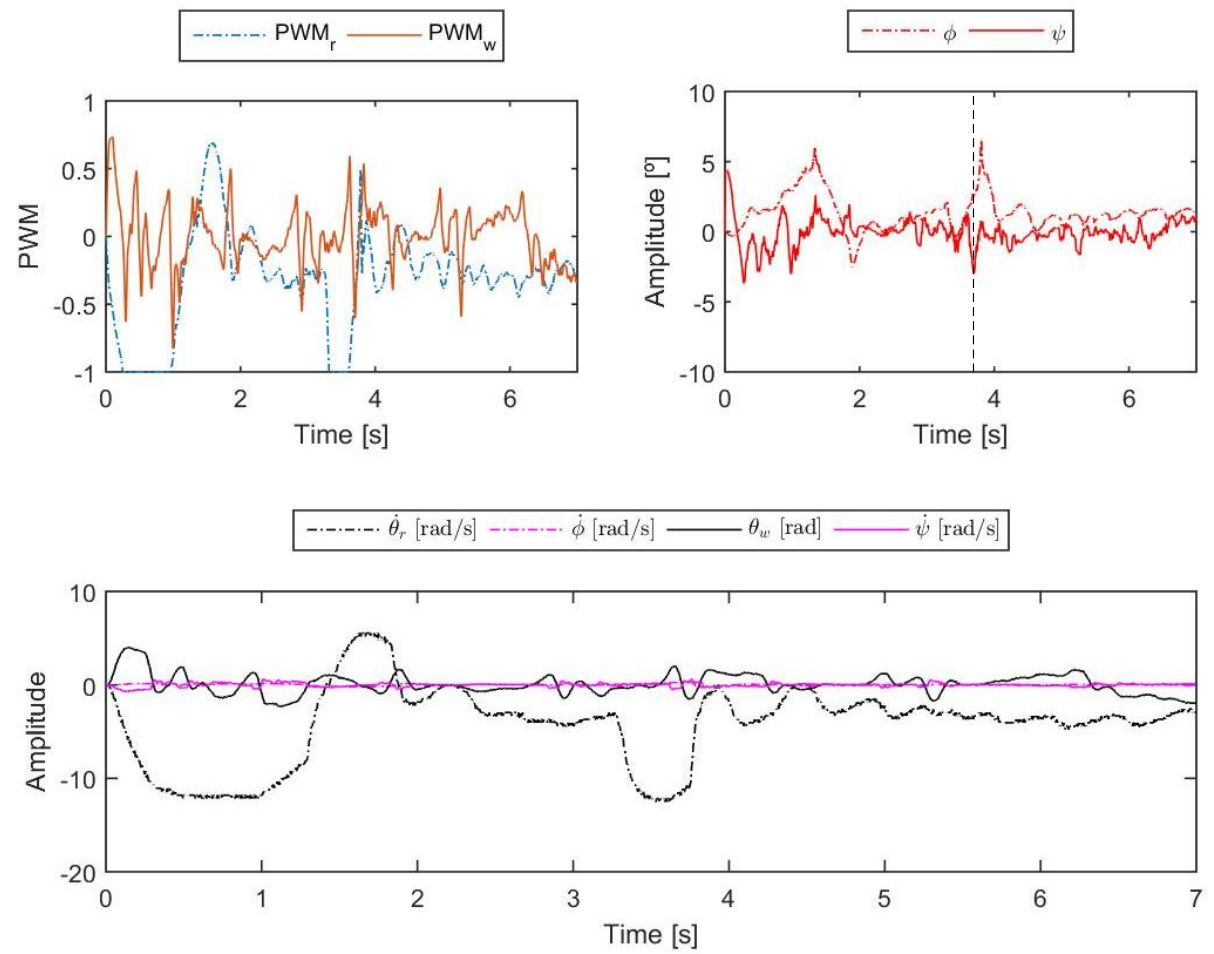

Source: Author. 
Figure 38: Practical pitch angle disturbance test with $\mathcal{H}_{2}$ controller.
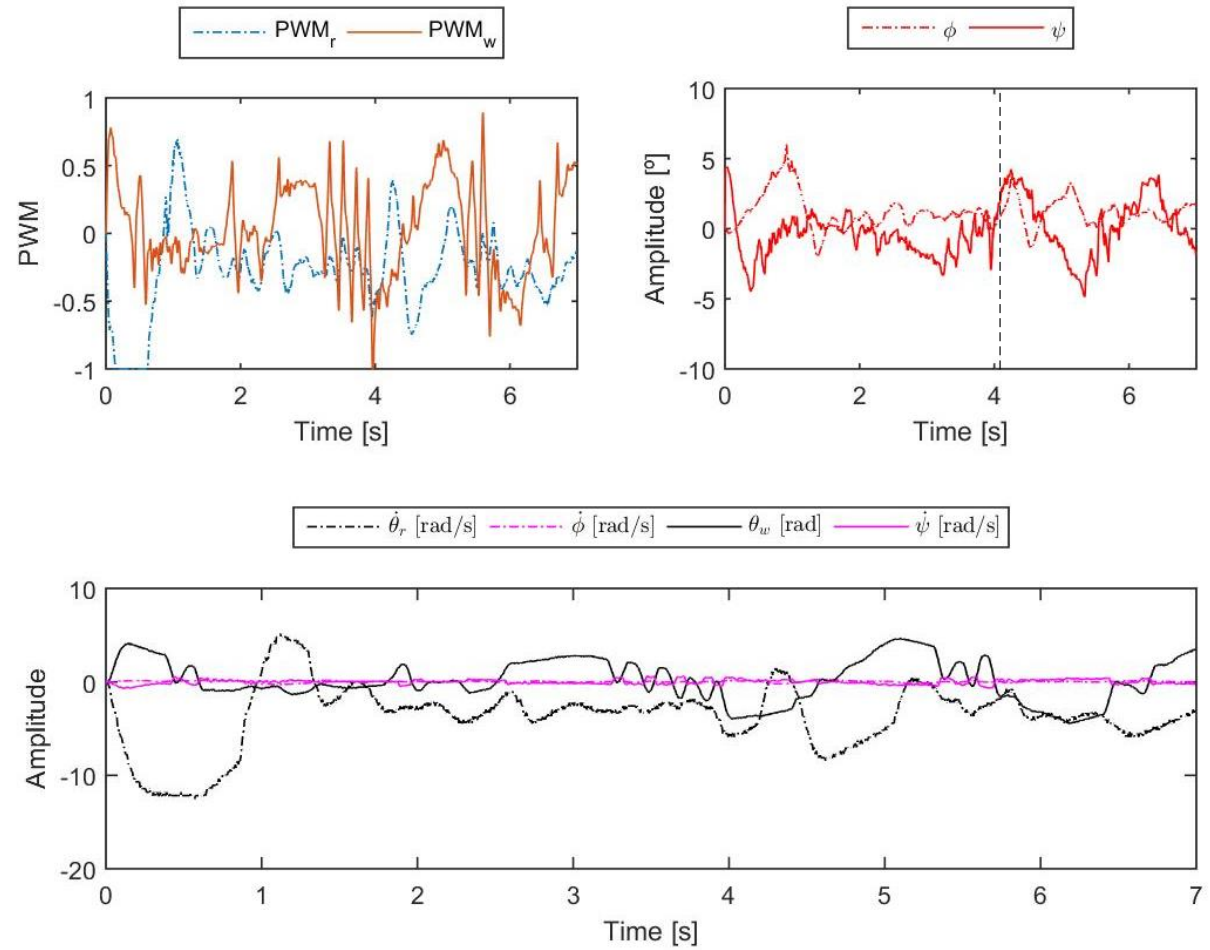

Source: Author.

Figure 39: Practical pitch and roll angle disturbance test with $\mathcal{H}_{2}$ controller.
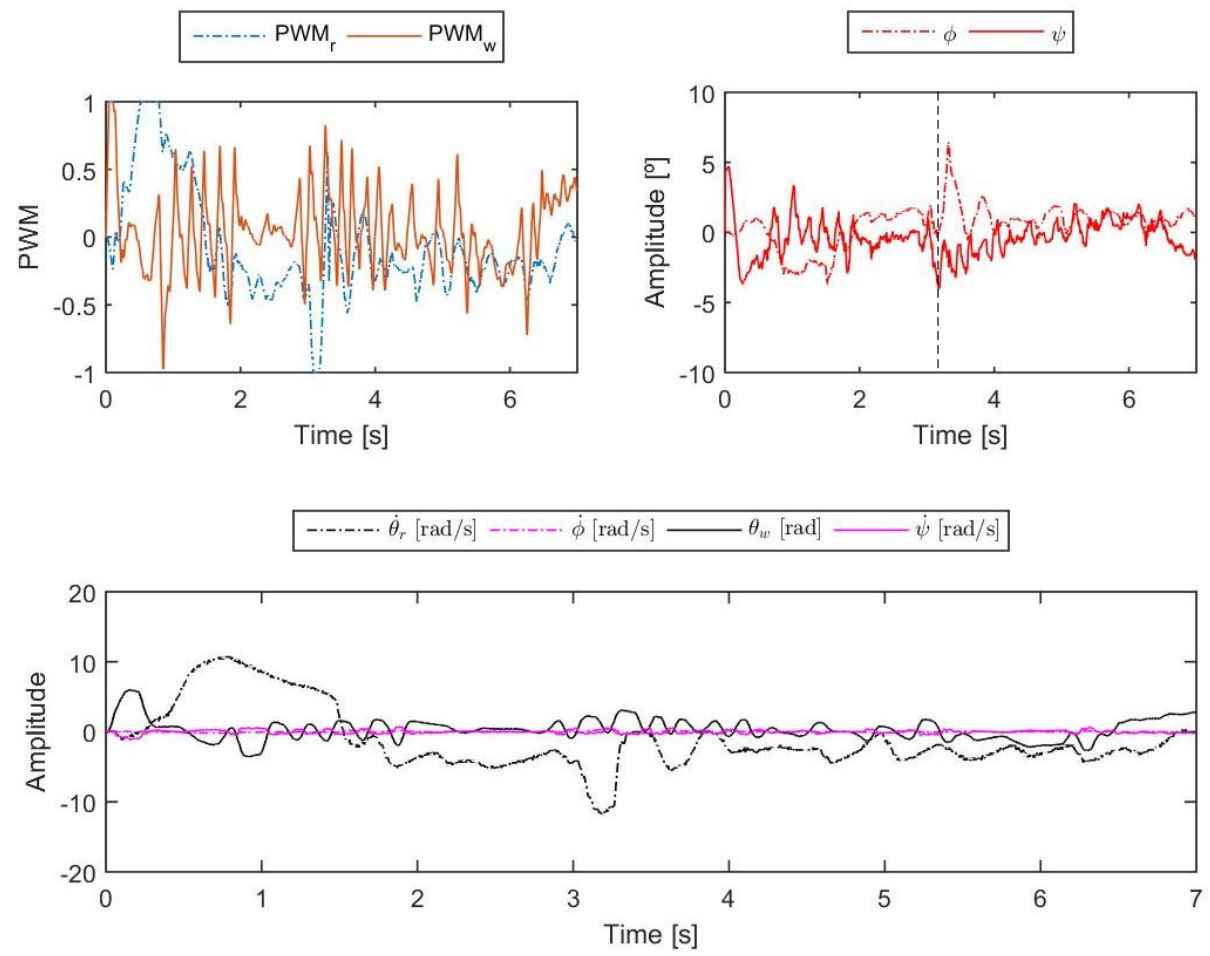

Source: Author. 
the control via LMI is the possibility of considering parametric uncertainties. In addition, in the $\mathcal{H}_{2}$ case with LMI, the $Q$ matrix was the same of the Bryson's method. In the LQR control, some trial and error tests were performed for adjusting the original $Q$ matrix.

A video with practical results can be seen in the link: < https://www.youtube.com/ watch?v=nTHvK6nyMlE $>$ 


\section{CONCLUSIONS}

The conclusion and suggestions of future works are presented in this chapter.

\subsection{Construction}

The construction of the prototype was satisfactory. As the electronic circuit and the wheels were made in a modular form, now it is relative simple to make changes and perform maintenance.

The components placement adjusted the position of the center of mass very close to the center of the body, as shown in Figure 40. This is very good because the ideal is to place the IMU sensor in the center of mass.

Figure 40: Position of the center of mass

(a) Back view.

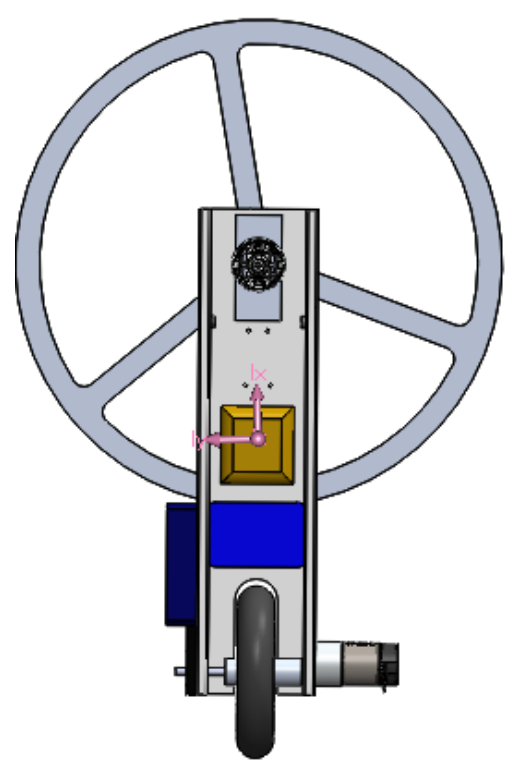

(b) Side view.

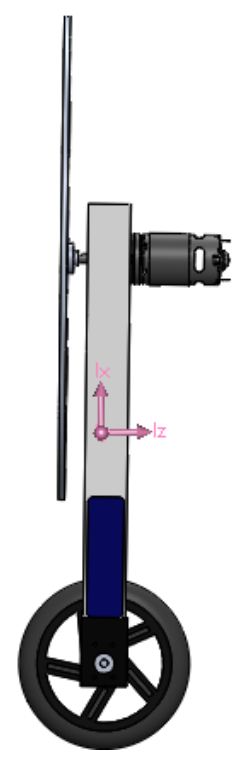

Source: Author

But some aspects of the construction presented problems. First, due to the size and weight of the unicycle, the reaction wheel had to be very large. Hence with the designed 
motor gearbox, the wheel speed almost reached saturation during the practical tests. Second, the gearbox and the wheel mounting resulted in backlash.

Another problem is the coupling of the two wheels, both presented backlash.

It is also important to mention that the system formed by the reaction wheel is very sensitive to some errors; a small variation in some parameters can already cause large differences in the control.

\subsection{Controller}

Regarding the controllers, both performed very well. The control system stabilized the plant in less than 2 seconds (considering an initial condition of $5^{\circ}$ ).

The controllers rejected the disturbances well by ensuring that the unicycle remains balanced, but, the actuators reached values very close of their limits. Therefore, the operation of the unicycle is well limited to angles close to zero; if any disturbance is strong enough for the angles to reach values much greater than zero, the actuators will not have enough power to stabilize the system. Hence, the current prototype it is not a good example to implement non-linear controllers.

For the LQR control it was necessary to change the matrix $Q$ (initially determined by the Bryson rule), but presented good practical results. In the first case, the designed controller worked in simulation, but not in practice. The system formed by the reaction wheel ended up unstable after a few seconds, probably due to some parameter uncertainty.

The LMI methodology was chosen to design a $\mathcal{H}_{2}$ controller considering uncertainties in some parameters. The controller performed well which suggests that the nominal values of the parameters are inaccurate.

During the design of the controller via LMI, it was observed that, when introducing parametric uncertainties, the resulting control coupled the pitch and roll angles. Therefore, the controller structure was fixed to maintain the decoupling of the plant.

With this, it can be concluded that the two design methodologies have their advantages, but the LMI control methodology allowed to guarantee a certain degree of robustness for parametric uncertainties, which is recommended for systems that suffer from parametric variations, such as the part formed by the reaction wheel of the unicycle. 


\subsection{Future works}

The first suggestion for future work is to improve the coupling of the wheels and motors. Currently, the wheels start to create a slack during operation, and after a while it is necessary to tighten the screws.

Second, to search for stronger actuators. As it was observed the actuators, mainly the reaction wheel motor, use too much of their power to stabilize the plant. Changing the actuators may allow a wider region of operation. Hence, a non-linear control could be compared with a linear one for larger initial conditions and larger disturbances.

Finally, to propose ways to guide the unicycle. It could be done in two different ways: adding one more reaction wheel along the $\vec{z}$ axis so that it controls the yaw angle, which is already presented in the literature, but little studied. Another way is to study the unicycle operation by making the reaction wheel speed tracking a reference, then check if the gyroscopic precession effect is sufficient to control the yaw angle. 


\section{REFERENCES}

AGUlhaRI, C. M.; OLIVEIRA, R. C. L. F. de; PERES, P. L. D. Robust LMI Parser: a computational package to construct LMI conditions for uncertain systems. In: XIX BRAZILIAN CONFERENCE ON AUTOMATION (CBA 2012). Proceedings... Campina Grande, PB, Brazil, 2012. p. 2298-2305.

BIN, H.; ZHEN, L. W.; FENG, L. H. The kinematics model of a two-wheeled self-balancing autonomous mobile robot and its simulation. In: COMPUTER ENGINEERING AND APPLICATIONS (ICCEA). Conference... [S.l.], 2010. v. 2, p. $64-68$.

BROWN, T. L.; SCHMIEDELER, J. P. Reaction wheel actuation for improving planar biped walking efficiency. IEEE Transactions on Robotics, v. 32, n. 5, p. 1290-1297, Oct 2016. ISSN 1552-3098.

CHOU, M. C. et al. Robust current and torque controls for pmsm driven satellite reaction wheel. IEEE Transactions on Aerospace and Electronic Systems, v. 47, n. 1, p. 58-74, January 2011. ISSN 0018-9251.

CRAIG, J. J. Introduction to Robotic: Mechanics and Control. 3th. ed. [S.l.]: Personal Education International, 2005. ISBN 0-13-123629-6.

DAOXIONG, G.; XIANG, L. Yaw control for a self-balancing unicycle robot with two flywheels. In: PROCEEDINGS OF THE 32ND CHINESE CONTROL CONFERENCE, 2013. Proceedings... [S.1.], 2013. p. 5576-5582.

DAOXIONG GONG; QI, P. G. Z. X. L. Lqr control for a self-balancing unicycle robot on inclined plane. Journal of System Design and Dynamics, v. 6, n. 5, p. 685-699, May 2012 .

FRAnKLIN, G.; POWELL, J.; WORKMAN, M. Digital Control of Dynamic Systems. 3th (reprint). ed. [S.l.]: Ellis-Kagle Press, 2006.

FURUTA, K.; YAMAKITA, M.; KOBAYASHI, S. Swing up control of inverted pendulum. In: INDUSTRIAL ELECTRONICS, CONTROL AND INSTRUMENTATION, 1991. Conference... [S.l.], 1991. p. 2193-2198 vol.3.

GEROMEL, R. H. K. J. C. Controle Linear de sistemas dinâmicos. 2th. ed. [S.l.]: Blucher, 2011. ISBN 978-85-212-0590-6.

GUO, L.; HE, K.; SONG, Y. Design of the sliding mode controller for a kind of unicycle robot. In: IEEE INTERNATIONAL CONFERENCE ON INFORMATION AND AUTOMATION (ICIA), 2016. Conferece... [S.l.], 2016. p. 1432-1437.

HAN, S. I.; LEE, J. M. Balancing and velocity control of a unicycle robot based on the dynamic model. IEEE Transactions on Industrial Electronics, v. 62, n. 1, p. 405-413, Jan 2015. 
HU, Z. et al. Design of lqr and pid controllers for the self balancing unicycle robot. In: INFORMATION AND AUTOMATION (ICIA), 2014 IEEE INTERNATIONAL CONFERENCE ON. Conferece... [S.1.], 2014. p. 972-977.

HWANG, J.; KIM, S.; LEE, J. Vision-based path planning for the rotation control of unicycle robot. In: IEEE/ASME INTERNATIONAL CONFERENCE ON ADVANCED INTELLIGENT MECHATRONICS. Conference... [S.l.], 2010. p. 1408-1412. ISSN 2159-6247.

JEPSEN, F. et al. Development and control of an inverted pendulum driven by a reaction wheel. In: INTERNATIONAL CONFERENCE ON MECHATRONICS AND AUTOMATION, 2009. Conference... [S.l.], 2009. p. 2829-2834. ISSN 2152-7431.

JIN, H. et al. Unicycle robot stabilized by the effect of gyroscopic precession and its control realization based on centrifugal force compensation. IEEE/ASME Transactions on Mechatronics, v. 21, n. 6, p. 2737-2745, Dec 2016. ISSN 1083-4435.

LEE, J.; HAN, S.; LEE, J. Decoupled dynamic control for pitch and roll axes of the unicycle robot. IEEE Transactions on Industrial Electronics, v. 60, n. 9, p. 3814-3822, Sept 2013.

MUEHLEBACH, M.; D'ANDREA, R. Nonlinear analysis and control of a reactionwheel-based 3-d inverted pendulum. IEEE Transactions on Control Systems Technology, v. 25, n. 1, p. 235-246, Jan 2017. ISSN 1063-6536.

OGATA, K. Engenharia de controle moderno. [S.l.]: Pearson Prentice Hall, 2011. ISBN 9788576058106 .

OLIVEIRA, M. C. de; SKELTON, R. E. Stability tests for constrained linear systems. London: Springer London, 2001. 241-257 p. ISBN 978-1-84628-576-9.

OLIVEIRA, R. C. L. F.; PERES, P. L. D. A convex optimization procedure to compute $h_{2}$ and $h_{\infty}$ norms for uncertain linear systems in polytopic domains. Optimal Control Applications and Methods, John Wiley \& Sons, Ltd., v. 29, n. 4, p. 295-312, 2008. ISSN 1099-1514.

ROSYIDI, M. A. et al. Speed and balancing control for unicycle robot. In: INTERNATIONAL ELECTRONICS SYMPOSIUM (IES), 2016. Proceedings... [S.l.], 2016. p. 19-24.

TANOS, A.; STEFFEN, T.; MAVROS, G. Improving lateral stability of a motorcycle via assistive control of a reaction wheel. In: UKACC INTERNATIONAL CONFERENCE ON CONTROL, 2014. Conference... [S.1.], 2014. p. 80-85. 


\section{APPENDIX A}

The terms of the matrix (3.22) are

$$
\begin{array}{r}
M_{11}=M_{12}=M_{21}=J_{r}, \\
M_{22}=J_{b w}+J_{r}+M_{b} R_{w}^{2}+M_{r} R_{w}^{2}+M_{w} R_{w}^{2} \cdots \\
+\left(2 L M_{b} R_{w}+2 L M_{r} R_{w}+2 M_{r} R_{w} d\right) \cos (\psi) \ldots \\
+\left(L^{2} M_{b}+L^{2} M_{r}+M_{r} d^{2}+2 L M_{r} d\right) \cos (\psi)^{2}, \\
M_{33}=J_{w}+M_{b} R_{w}^{2}+M_{r} R_{w}^{2}+M_{w} R_{w}^{2}, \\
M_{34}=M_{43}=R_{w} \cos (\psi)\left(M_{r} d+L M_{b}+L M_{r}\right), \\
M_{44}=J_{b r}+L^{2} M_{b}+L^{2} M_{r}+M_{r} d^{2}+2 L M_{r} d .
\end{array}
$$


For matrix (3.23), the terms are:

$$
\begin{aligned}
& V_{1}=\frac{K_{e r} K_{t r} n_{r}\left(n_{r} \dot{\theta_{r}}\right)}{R_{e r}}-B_{v r} \theta_{r} \\
& V_{2}=\frac{-K_{e r} K_{t r} n_{r}\left(n_{r} \dot{\theta}_{r}\right)}{R_{e r}}-\left(2 L M_{b}+2 L M_{r}+2 M_{r} d\right) R_{w} \dot{\varphi} \dot{\psi} \sin (\psi) \ldots \\
& -\left(L^{2} M_{r}+L^{2} M_{b}+M_{r} d^{2}+2 L M_{r} d\right) \dot{\varphi} \dot{\psi} \sin (2 \psi)-B_{v r} \theta_{r} \\
& V_{3}=\frac{K_{e w} K_{t w} n_{w}\left(n_{w} \dot{\theta_{w}}-\dot{\psi}\right)}{R_{e w}}-\left(M_{r} d+L M_{b}+L M_{r}\right) R_{w} \dot{\psi}^{2} \sin (\psi)+B_{v w} \theta_{w} \\
& V_{4}=\frac{-K_{e w} K_{t w} n_{w}\left(n_{w} \dot{\theta_{w}}-\dot{\psi}\right)}{R_{e w}}+\left(L M_{b}+L M_{r}+M_{r} d\right) R_{w} \dot{\varphi}^{2} \sin (\psi) \ldots \\
& \left(\frac{\left(L^{2} M_{b}\right)}{2}+\frac{\left(L^{2} M_{r}\right)}{2}+\frac{\left(M_{r} d^{2}\right)}{2}+L M_{r} d\right) \dot{\varphi}^{2} \sin (2 \psi)+B_{v w} \theta_{w},
\end{aligned}
$$

Finally, for matrix (3.24)

$$
\begin{array}{r}
G_{2}=-g \sin (\varphi)\left(\left(M_{b}+M_{r}+M_{w}\right) R_{w}+\left(L M_{b}+L M_{r}+M_{r} d\right) \cos (\psi)\right) \\
G_{4}=-g \cos (\varphi) \sin (\psi)\left(M_{r} d+L M_{b}+L M_{r}\right) .
\end{array}
$$




\section{APPENDIX B}

The Simulink diagram simulation was composed of three blocks. Figure 41 shows the principal diagram and Figure 42 shows the block of the dead zone, saturation and first order filter. Figures 43 presents the torque calculated and Figure 44 the noise addition and derivate calculation.

Figure 41: Principal Diagram.

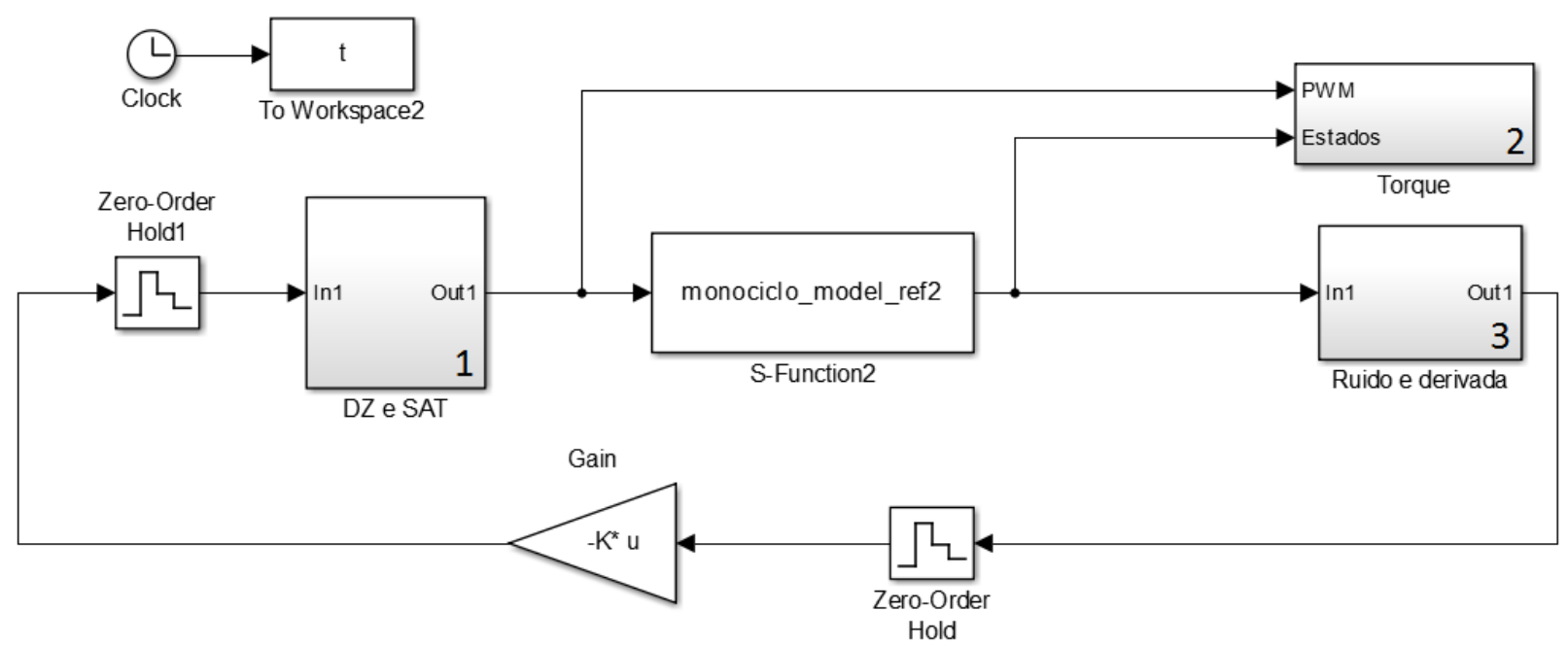

Source: Author. 
Figure 42: Block 1.

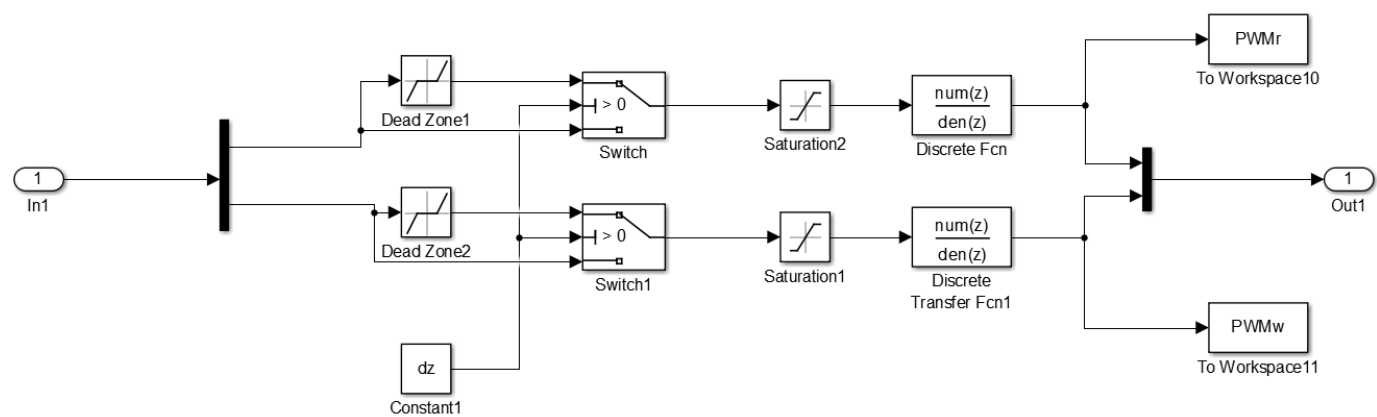

Source: Author.

Figure 43: Block 2.

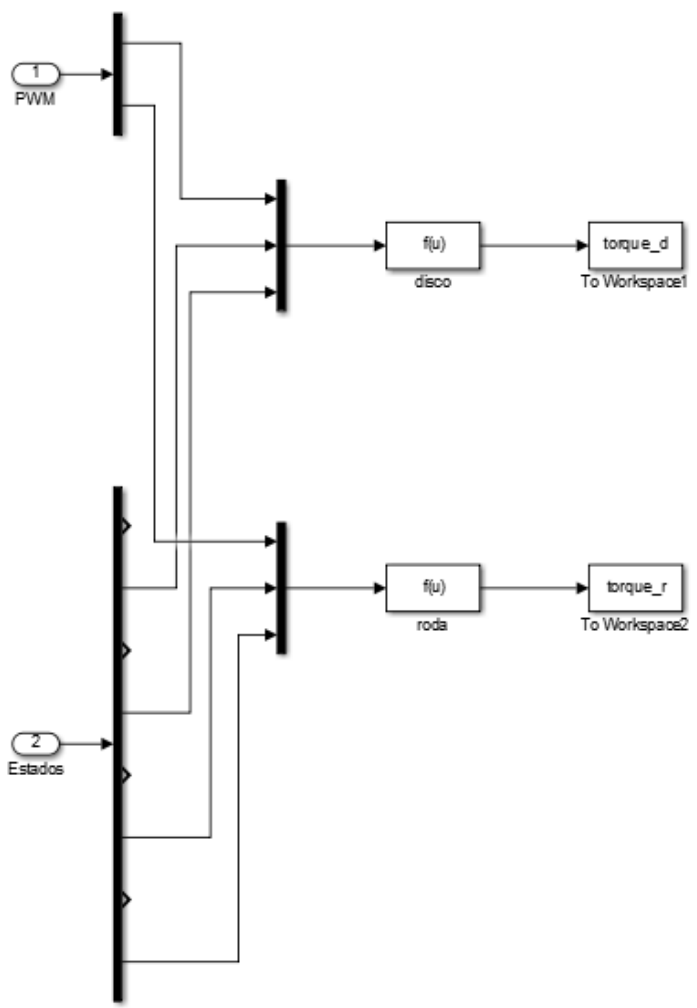

Source: Author. 
Figure 44: Block 3.

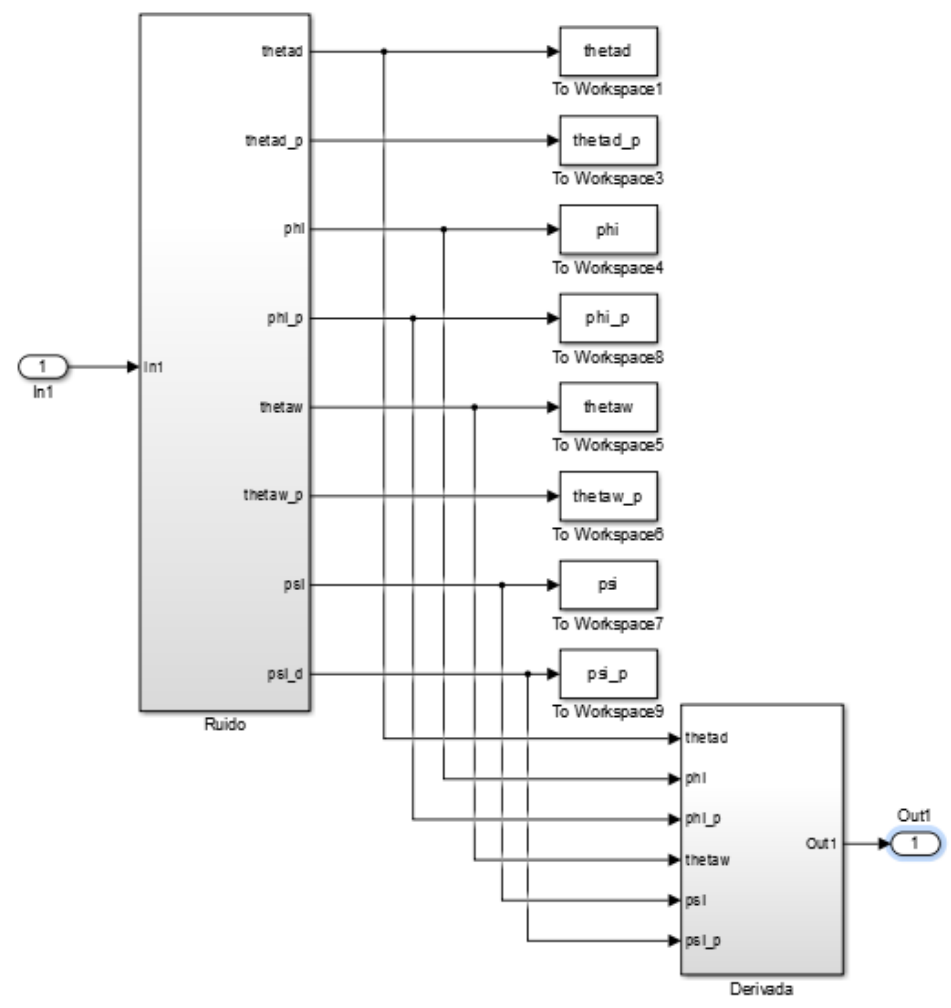

Source: Author. 